\title{
AID and APOBECs span the gap between innate and adaptive immunity
}

\author{
Arnaud Moris ${ }^{1,2,3,4} *$, Shannon Murray ${ }^{1,2,3+}$ and Sylvain Cardinaud ${ }^{1,2,3 \dagger}$ \\ ${ }^{1}$ Center for Immunology and Microbial Infections, Faculty of Medicine, Université Paris-Sorbonne, UPMC Univ Paris 06, Paris, France \\ ${ }^{2}$ Center for Immunology and Microbial Infections, Institut National de la Santé et de la Recherche Médicale, U1135, Paris, France \\ ${ }^{3}$ Center for Immunology and Microbial Infections, Centre National de la Recherche Scientifique, ERL 8255, Paris, France \\ ${ }^{4}$ Department of Immunology, Hôpital Pitié-Salpêtière, Paris, France
}

\section{Edited by:}

Nadine Laguette, Centre National de la Recherche Scientifique, France

\section{Reviewed by:}

Dorian Mcllroy, University of Nantes, France

Joao Goncalves, Faculdade de Farmácia da Universidade de Lisboa Portugal

\section{${ }^{*}$ Correspondence:}

Arnaud Moris, Center for Immunology and Microbial Infections, Faculty of Medicine, Université Paris-Sorbonne, 91 Boulevard de l'Hôpital, 75013 Paris Cedex 13, France

e-mail: arnaud.moris@upmc.fr

${ }^{\dagger}$ Present address:

Shannon Murray, Vaccine and Gene Therapy Institute of Florida, 9801 SW Discovery Way, Port Saint Lucie, FL 34987, USA;

Sylvain Cardinaud, INSERM U955, IMRB Equipe 16, Vaccine Research Institute, Hôpital Henri Mondor, 94010 Créteil, France
The activation-induced deaminase (AID)/APOBEC cytidine deaminases participate in a diversity of biological processes from the regulation of protein expression to embryonic development and host defenses. In its classical role, AID mutates germline-encoded sequences of $B$ cell receptors, a key aspect of adaptive immunity, and APOBEC1, mutates apoprotein B pre-mRNA, yielding two isoforms important for cellular function and plasma lipid metabolism. Investigations over the last ten years have uncovered a role of the APOBEC superfamily in intrinsic immunity against viruses and innate immunity against viral infection by deamination and mutation of viral genomes. Further, discovery in the area of human immunodeficiency virus (HIV) infection revealed that the HIV viral infectivity factor protein interacts with APOBEC3G, targeting it for proteosomal degradation, overriding its antiviral function. More recently, our and others' work have uncovered that the AID and APOBEC cytidine deaminase family members have an even more direct link between activity against viral infection and induction and shaping of adaptive immunity than previously thought, including that of antigen processing for cytotoxic $T$ lymphocyte activity and natural killer cell activation. Newly ascribed functions of these cytodine deaminases will be discussed, including their newly identified roles in adaptive immunity, epigenetic regulation, and cell differentiation. Herein this review we discuss AID and APOBEC cytodine deaminases as a link between innate and adaptive immunity uncovered by recent studies.

Keywords: restriction factors, CTL, HIV, correlate of protection, APOBEC1, APOBEC2, APOBEC3

\section{INTRODUCTION}

Higher eukaryotes have developed multiple strategies to counteract viral infections. A first line of defense is based on the recognition of pathogen-associated molecular patterns (PAMPs) such as viral replication intermediates that are molecules not commonly found in uninfected host cells. PAMPs were originally defined as molecular patterns specific to microbes, highly conserved and required for microbial function, and thus, are selfnonself discriminating molecules for higher eukaryotic organisms. After the engagement of PAMPs with the subsequently identified PAMP receptors, activation of a cascade of events leads to the expression and, in some cases, secretion of antiviral molecules and chemokines. Some of these molecules have been defined as "restriction factors" meaning host factors that have been evolutionarily selected for based on their capacity to restrict microbial infections. The receptors and effectors of this innate immunity are germline-encoded and mediate key aspects of host defense. However, viruses can also evade host defenses. It is the second arm of the immune system, adaptive immunity, which provides flexible antigen recognition based on somatic modification of antigen receptor genes in immune cells. This process involves selection of immune cells that includes a step of deletion of antigen receptors that are self-reactive, thus preventing autoimmunity, while allowing adaptation to diverse pathogens and the establishment of rapid and robust memory responses. There is evidence that communication between innate and adaptive immunity is required to clear pathogen infections that are otherwise deleterious to the host (Iwasaki and Pillai, 2014). Innate and adaptive immunity are thus considered interdependent.

Activation-induced deaminase (AID) and APOBEC (apolipoprotein B mRNA editing enzyme, catalytic polypeptide-like) enzymes are important in both innate and adaptive immune responses. AID/APOBEC family members originate from a large gene superfamily encoding for zinc-dependent deaminases involved in the metabolism of purine and pyrimidine bases (Conticello, 2008). The appearance of AID/APOBECs is thought to be concurrent with the divergence of the vertebrate lineage and the evolution of adaptive immunity (Conticello, 2008). AID/APOBECs have a unique capacity to mutate DNA and/or RNA of both host and pathogen as a result of their ability to deaminate cytidine to uridine. This activity, referred to as nucleic acid "editing," is involved in various immune functions, including restriction of viral replication, antigen presentation, and maturation of host immune receptors. The structure of AID/APOBEC proteins in relation with their editing activities has been recently reviewed (Conticello et al., 2007; Desimmie et al., 2014). AID is 
thought to be the oldest member of the family and is essential for antigen-driven $\mathrm{B}$ cell terminal differentiation and antibody (Ab) affinity maturation and diversification (Muramatsu et al., 2000). In humans, genetic deficiency of AID leads to Type-2 Hyper-IgM Syndrome (HIGM2), an immunodeficiency characterized by the absence of antibodies other than the IgM class (Revy et al., 2000). APOBEC1, the first family member to be identified, plays an important role in lipid metabolism due to its ability to edit the apopoliprotein B (ApoB) pre-mRNA (Navaratnam etal., 1993; Teng et al., 1993). APOBEC1 might also participate in the restriction of viral infections (Ikeda et al., 2008; Gonzalez et al., 2009). APOBEC3s include seven members (A-C, DE, and $\mathrm{F}-\mathrm{H}$ ) that are involved in the restriction of viral infection and propagation affecting viruses such as human immunodeficiency virus (HIV), hepatitis C virus ( $\mathrm{HCV})$, and hepatitis B virus (HBV). APOBEC2 and APOBEC4 functions remain poorly understood although a role of APOBEC2 in embryogenesis has been recently proposed (Vonica et al., 2010). Highlighting the crucial role of AID/APOBECs in host defense, viruses have developed mechanisms to interfere with AID/APOBEC biogenesis and/or functions, and in fact, APOBEC3G was originally discovered due to its interaction with the HIV Vif protein (Sheehy etal., 2002). Here, we will review the cellular functions of AID/APOBEC family members and discuss recent work investigating their contribution in innate and adaptive antiviral immunity.

\section{CELLULAR FUNCTIONS OF AID AND APOBEC FAMILY MEMBERS

In humans, APOBEC1 (A1) is uniquely expressed in the gastrointestinal tract and participates in plasma lipid metabolism. In other species, such as mice, rats, horses, and dogs, A1 is also present in the liver (Greeve etal., 1993). Until recently, ApoB pre-mRNA was thought to be the single cellular target of A1 (Teng et al., 1993). ApoB protein has two isoforms, ApoB100 and ApoB-48, encoded by a single gene in the liver and small intestine, respectively. The shortest form, ApoB-48, is the product of Al editing activity and corresponds to the $\mathrm{N}$ terminal portion of ApoB. Al converts a unique cytidine to uridine (at position 6666 in Apo pre-mRNA) leading to a glutamine to STOP codon substitution and ApoB-48 translation (Navaratnam etal., 1993). ApoB-100 and ApoB-48 have different biological properties and control the homeostasis of plasma cholesterol. The editing activity of A1 is therefore an important determinant for plasma concentrations of ApoB-containing lipoproteins that are implicated in development of hyperlipidemia and atherosclerosis. Overexpression of A1 in the liver of mice or rabbits reduces the concentration of low-density lipoproteins. However, A1 overexpression also induces hepatocellular carcinoma in transgenic animals (Yamanaka et al., 1995), most likely due to its capacity to edit DNA (Harris et al., 2002; Petersen-Mahrt and Neuberger, 2003). A1 is indeed expressed in the nucleus where ApoB pre-mRNA editing also occurs (Lau et al., 1991).

More recently, using a transcriptome-wide RNA sequencing screen comparing wild type and A1-deficient mice, Papavasilou et al. discovered that, in small intestine, many mRNA transcripts other than apoB are edited by A1 (Rosenberg et al., 2011). The targets of A1 are $3^{\prime}$-untranslated regions ( $3^{\prime}$ UTR) of mRNA transcripts, suggesting additional roles for APOBEC1 beyond its function in ApoB regulation.

\section{AP0BEC2}

A2 was cloned based on its sequence homology with A1 (Liao et al., 1999). A2 is well-conserved in the vertebrate lineages and can be traced back to bony fish (Liao et al., 1999; Etard et al., 2010). Using in vitro models (e.g., Escherichia coli), A2 has been shown to exhibit intrinsic cytidine deaminase activity (Liao et al., 1999). Although the A2 structure has been solved (Prochnow et al., 2007), its functions remained elusive until recently. In humans, $\mathrm{A} 2$ is exclusively expressed in heart and skeletal muscles (Liao et al., 1999). In mice, A2 $\mathrm{KO}$ was reported to have no major effect on animal viability and fertility (Mikl et al., 2005). This is in contrast to recent studies that implicate A2 in embryonic development of fish and xenopus (Etard et al., 2010; Pennings et al., 2010; Vonica et al., 2010). The lack of A2 expression causes a dystrophic muscle phenotype in zebrafish embryos (Etard et al., 2010). A2 seems to inhibit TGF $\beta$ signaling, thus promoting muscle fiber differentiation both in vivo (in zebrafish and xenopus embryos) but also in vitro using a mammalian myoblastic cell line (Vonica et al., 2010). The mechanism of action and the targets of $\mathrm{A} 2$ action during embryogenesis are not defined, however, the ability of A2 (and other deaminases such as AID) to deaminate methylated cystidines suggests a possible role in epigenetic regulation (Rai et al., 2008).

\section{AID}

Activation-induced deaminase was cloned in a subtractive cDNA library screen comparing activated and resting B cell lymphomas (Muramatsu et al., 1999). AID is a key determinant in the generation of protective $\mathrm{Ab}$-mediated adaptive immune responses. The cytidine deaminase activity of AID initiates the introduction of double stranded DNA breaks (DSB) in the immunoglobulin heavy chain ( $\mathrm{IgH}$ ) gene locus allowing $\mathrm{Ab}$ diversification, referred to as class switch recombination (CSR; Muramatsu et al., 2000). In addition, AID produces point mutations at the $\mathrm{V}(\mathrm{D}) \mathrm{J}$ region of $\mathrm{Ig}$ loci, a mechanism referred to as somatic hypermutation, (SHM), allowing B cell maturation (Muramatsu et al., 2000). These functions require a rigorous targeting of AID activities to SHM and CSR substrates (Kohli et al., 2010). Targeting might involve several complementary mechanisms such as AID binding to replication protein $\mathrm{A}$, a ssDNA-binding protein involved in DNA repair (Basu et al., 2005), and/or association with a non-encoding RNAprocessing/degradation complex (Basu et al., 2011). The editing activity of AID is not restricted to Ig loci and AID can act on a wide spectrum of genomic targets in B cells (Yamane et al., 2011). As a consequence, aberrant expression of AID promotes cancer development in animal models and humans (Okazaki et al., 2007). Dysregulated expression of AID facilitates DNA translocations that require DSB such as $c-m y c / I g H$ found in Burkitt's lymphoma and $c-m y c / m i R-142$ found in B cell leukemia (Robbiani et al., 2008, 2009; Hasham et al., 2010). Constitutive or ubiquitous AID expression also leads to cancer development that is characterized by point mutations in oncogenes as well as passenger mutations 
(those mutations that do not contribute to cancer growth; Okazaki et al., 2003). AID can therefore produce mutations in many genes other than Ig genes. While most of these mutations are rapidly repaired by the cellular DNA-repair machinery, those that are not successfully repaired, can destabilize the genome of cells.

Although AID expression is at its highest levels in germinal center B cells that undergo CSR and SHM, it is also found in other cell types such as oocytes, embryonic stem (ES) cells, and in estrogen-induced breast tissue (Fritz and Papavasiliou, 2010). The function of AID expression in these cells or tissues remains to be elucidated. However, the study of lower vertebrates including zebrafish suggests that AID expression is involved in epigenetic reprogramming of germ cells during early development (Rai et al., 2008). Using an AID knockout mouse model, Popp etal. (2010) revealed a role of AID in DNA demethylation during primordial germ cell reprogramming. DNA cytosine methylation is associated with gene silencing and plays a key role in development and genomic imprinting. The removal of 5-methyl group on cytosine $(5-\mathrm{mC})$ contributes to epigenetic reprogramming required for the restoration of pluripotency of germ cells. Several lines of evidence suggest that AID, but also A1 and A2, might participate in this process of demethylation: AID and A1 can deaminate 5-methylcytosine in vitro and in E. coli (Morgan et al., 2004), and germ cells from AID-deficient mouse exhibit a hypermethylation pattern (Popp et al., 2010). AID (and A2) might contribute to the conversion of $5-\mathrm{mC}$ to thymidine $(\mathrm{T})$ later replaced by cytosine $(\mathrm{C})$ by the DNA-repair machinery (Rai et al., 2008). In summary, AID function is not limited to Ab diversification, and evidence is accumulating to suggest a role in epigenetic reprogramming.

\section{APOBEC3s}

Sheehy et al. (2002) initially discovered the first family member of APOBEC3, A3G, in ground-breaking studies with HIV infection. Since that original identification, seven human A3 genes clustered in tandem on chromosome 22 have been identified, namely, A3A, A3B, A3C, A3DE, A3F, A3G, and A3H, which most likely arose through gene duplication of a single-copy primordial gene (Jarmuz et al., 2002). A3E was thought to be a pseudogene but in fact, $\mathrm{A} 3 \mathrm{D}$ and $\mathrm{A} 3 \mathrm{E}$ form one unique protein $(\mathrm{A} 3 \mathrm{DE}$; Dang etal., 2006). All A3 genes encode one or two conserved zinc-coordinating deaminase domain (ZDD), which contains a His/Cys-Xaa-Glu-Xaa 23 -28-Pro-Cys-Xaa 2 -4-Cys signature motif [X denotes any amino acid (aa)]. Regions of human A3 mRNAs share between 30 and 100\% homology. Interestingly, depending on the species, the A3 genes expanded and/or contracted. As a result, $\mathrm{A} 3$ gene number ranges from one (mice, rats, pigs) to three (cats) and six (horses; LaRue et al., 2008). In humans, A3 genes are also highly polymorphic most likely due to the fact that they have been under strong and continuing selective pressure during primate evolution (Conticello et al., 2005; Henry et al., 2012). As discussed later on in this review, A3 polymorphisms might influence their specific antiviral activity.

A3 gene expression has been mainly documented in immune cells and these results have been determined based on mRNA levels in cells, using quantitative PCR (Koning etal., 2009; Refsland et al., 2010). This approach is particularly difficult since
A3 genes are highly homologous and polymorphic. Apart from A3G and A3A, most antibodies to A3s are not very specific and endogenous A3 proteins are often difficult to detect. Nonetheless, several studies indicate a strong correlation between mRNA level and protein expression (Refsland et al., 2010). There is a general consensus that most A3s are highly expressed in T cells [memory or naïve (Refsland et al., 2010)] but also in B cells and phagocytic cells. A3A and $\mathrm{A} 3 \mathrm{~B}$ are predominantly expressed in monocytes (Peng et al., 2007; Thielen et al., 2010) and B lymphocytes (Koning et al., 2009), respectively. A3G and A3F are expressed in T cells, monocytes and dendritic cells (DC; Sheehy et al., 2002; Pion et al., 2006; Peng et al., 2007; Pido-Lopez et al., 2007; Stopak et al., 2007; Trapp et al., 2009). However, there is no consensus regarding their relative abundance. A3s expression is not confined to immune cell populations, and are highly expressed in human testis and ovary (A3G and A3F) (Koning et al., 2009) as well as ES cells (A3B, A3C, A3DE, A3F, and A3G; Wissing et al., 2011). A3G, A3F, A3B, and A3C are expressed in primary hepatocytes (Bonvin et al., 2006; Tanaka et al., 2006). The true breadth of basal A3 expression in human tissues remains difficult to estimate as leukocytes infiltrate tissues and no suitable specific immunohistochemistry antibodies are presently available. Nevertheless, different observations are in favor of a broad and constitutive A3 expression profile in human tissues. For instance, various cancer cell lines of non-immune origin - colorectal adenocarcinoma, melanoma and lung carcinoma lines - express multiple human A3s. It is possible that A3 expression is induced during oncogenesis, but given the abundance of $\mathrm{A} 3 \mathrm{~s}$ in different cell types it might also reflect their normal expression profile prior to cell transformation.

The cellular expression of A3s clearly indicates a role of A3s in immunity. The broad distribution of A3s also points toward a putative role in cellular maintenance. A3G and A3F localize in cytoplamic microdomains and stress granules that are sites of RNA storage and metabolism also called mRNA-processing bodies (or P-bodies; Wichroski et al., 2006; Gallois-Montbrun et al., 2008). Within P-bodies, A3G and A3F interact with effectors of the RNA silencing machinery (such as Argonaute 1 and 2) and translation suppressor (RCK/p54), suggesting that A3G-F participate in RNA metabolism and fate determination (Wichroski et al., 2006; Gallois-Montbrun et al., 2008). However, Phalora etal. (2012) found no evidence that A3s participate in specific regulation of miRNA. In addition, the manipulation of P-bodies using siRNA inhibition had no impact of A3 antiviral functions and HIV replication (Phalora et al., 2012). The reason why $\mathrm{A} 3 \mathrm{G}$ and $\mathrm{A} 3 \mathrm{~F}$ localize to these $\mathrm{P}$-bodies remains unclear. More recently, a role of A3s in DNA catabolism has also been proposed. Reminiscent of AID capacity to deaminate $\mathrm{B}$ cell genomes (during SHM and CSR), A3A edits host nuclear and mitochondrial DNA leading to the introduction of uridine (Suspene etal., 2011a). In the presence of functional DNA repair machinery, most mutations are likely fixed. In contrast, in uracil DNA-glycosylase (UNG)-deficient cells, (UNGs are enzymes required for excision of uracil bases), cytidine deaminations are readily detected using differential DNA-denaturation PCR (3D-PCR) (Suspene et al., 2011a). The significance of nuclear DNA editing by $\mathrm{A} 3 \mathrm{~A}$ is rather enigmatic as hyperediting is 
synonymous with cell death and aberrant editing and/or repair might contribute to tumorigenesis (Mussil et al., 2013). On the other hand, phagocytic cells that express predominantly A3A may use cytidine-deamination to mark foreign DNA for degradation. In this model, the deamination of multiple cytidines on foreign DNA might lead to uracil excision by UNG, creating nuclease-sensitive abasic sites, and subsequent degradation by cellular nucleases (Stenglein et al., 2010). The nucleases involved have not been characterized, but as discussed by Stenglein et al. (2010) might include the IFN-inducible APEX or TREX1, though a contribution of DNAse I and II cannot be ruled out. This mechanism might represent an intrinsic immune defense reminiscent of bacteria that evolved endonucleases to prevent DNA transmission and bacteriophage infection (Stenglein et al., 2010). To this regard it is interesting to note that A3A and other A3s are induced upon inflammation (as described further, below).

Much remains to be learned regarding the cellular functions of A3s. Depending on cell type and tissue environment, A3s differently contribute to DNA/RNA deamination and their overarching biological roles are still being elucidated.

\section{AID, APOBEC1, AND APOBEC2 IN ANTIVIRAL IMMUNITY APOBEC1}

The sequence homology between A1 and A3G prompted researchers to investigate a potential role of $\mathrm{A} 1$ in viral infection (Bishop et al., 2004a,b). In a pioneering work, Bishop et al. (2004b) demonstrated that human A1 (hA1) incorporated into HIV particles had no effect on HIV replication. In contrast, rat Al had a strong suppressive effect on HIV regardless of Vif expression (Bishop et al., 2004b). Later work confirmed that in contrast to hA1, A1 from small animals (e.g., rabbit, hamster, mouse) inhibited the replication of retroviruses such as SIV (simian immunodeficiency virus), FIV (feline immunodeficiency virus), and murine leukemia virus (MLV), and the activation of autonomous retroelements in a deaminase-dependent manner, thus suggesting a putative role for A1 in the restriction of viral replication (Ikeda et al., 2008). The demonstration that A1 is a restriction factor in the course of viral infections in natural hosts came from the study of MLV and hepadnaviruses by the group of Wain-Hobson and Vartanian (Petit et al., 2009; Renard et al., 2010). Analyzing viral sequences in HBV-infected chimpanzees, woodchucks chronically infected with the natural woodchuck hepatitis virus (WHV) as well as ducks infected with duck hepatitis virus (DHV), the authors provided evidence that A1 edits hepadnaviral genomes and restricts replication in vivo (Renard et al., 2010). Analyzing human serum from two HBV chronically infected carriers, the same group also suggested that A1 edits HBV genomes in vivo (Gonzalez et al., 2009). These results were somehow surprising due to the fact that in humans A1 is not normally expressed in the liver. However, viral infection might lead to ectopic expression of A1. During the course of viral infections, the influence of IFN induction (or treatment) on Al expression has not been investigated thus far. Nonetheless, the function of A1 is most likely not limited to the regulation of lipid metabolism. In vertebrates, A1 likely participates in intrinsic defenses against some viral infections.

\section{APOBEC2}

Though A2 exhibits deaminase activities (Liao et al., 1999), it has not been assigned a role in the restriction of viral replication thus far. However, it is interesting to note that in hepatocytes, A2 expression is enhanced by pro-inflammatory cytokines such as TNF $\alpha$ and IL-1 $\beta$ (Matsumoto et al., 2006). A2 contains functional $\mathrm{NF}-\mathrm{kB}$ response elements in the $5^{\prime}$ untranslated region, suggesting a possible involvement in immune responses (Matsumoto et al., 2006). In the tonsils of patients with Immunoglobulin A nephropathy (IgAN) a disease characterized by IgA deposition to glomerular mesangial cells and glomerulonephritis, A2 expression is up-regulated around B cell germinal centers (where B cells undergo CSR and SHM with the "help" of follicular T cells). However, a direct role of A2 in IgAN pathology or IgA production has not been established (Iio et al., 2010).

\section{AID}

As discussed earlier, AID is required for CSR and, as a result, is critical for the generation of $\mathrm{B}$ cells that secrete Abs with various effector functions and tissue distribution in the organism (Muramatsu etal., 2000). For instance, immunoglobulins of the IgA isotype are found at the portal of pathogen entry in the mucosa and can be transported across the epithelium to neutralize pathogens. IgG is the principal isotype in the blood and extracellular fluid and is involved in pathogen neutralization, opsonization, and complement activation. AID $-/-$ mice harbor a complete defect of CSR with a hyper-IgM phenotype and present enlarged germinal centers containing activated $\mathrm{B}$ cells (Muramatsu etal., 2000). In addition, AID involvement in SHM allows the generation of $\mathrm{B}$ cells with the potential to secrete Abs with higher affinities (Imai et al., 2003). Interestingly, mice carrying a mutated allele of AID with reduced capacity to perform SHM but with normal amounts of CSR, exhibit an impaired gut homeostasis and inefficient mucosal defenses (Wei et al., 2011). In humans, genetic deficiencies of AID are responsible for the development of a rare immunodeficiency, HIGM2 (Revy et al., 2000). HIGM2 is characterized by the absence of antibodies other than IgM and a profound susceptibility to bacterial infections (Revy et al., 2000). AID is therefore a key determinant in protective immunological responses, and the most well-documented mechanism of this protection is through the generation of protective $\mathrm{Ab}$-mediated immune responses.

The action of AID is not limited to B cell differentiation and maturation as there is accumulating evidence that AID contributes to innate defenses against viruses. For example, HCV, EpsteinBarr virus (EBV), and Kaposi's sarcoma-associated herpesvirus (KSHV) have been shown to induce AID expression in B cells residing outside the germinal centers (Machida et al., 2004; Rosenberg and Papavasiliou, 2007; Bekerman et al., 2013). It is unclear so far whether AID up-regulation is beneficial or deleterious to $\mathrm{HCV}$ and EBV, however, in the case of KSHV, AID has a direct impact on viral fitness by inhibiting lytic reactivation and by reducing infectivity of virions. Further reinforcing the role of AID in antiviral responses, KSHV encodes microRNAs that dampen AID expression (Bekerman et al., 2013). Whether the deaminase activity of AID is required for KSHV restriction [as described 
for $\mathrm{A} 3 \mathrm{G}$ (see below)] remains to be determined. In hepatocytes, AID expression also correlates with reduced susceptibility to HBV infection (Watashi et al., 2013), a mechanism that might be dependent on deamination of the HBV genome by AID (Liang et al., 2013). AID might also participate in responses against transforming retroviruses. AID-deficient mice have been shown to be more susceptible to Abelson murine leukemia virus (A-MuLV), a defective virus that causes pro-B cell leukemia in vivo (Gourzi et al., 2006). In this case, the action of AID does not involve direct editing of the viral genome. Instead, AID might cause damage in the host cell genome, resulting in cell cycle arrest and/or up-regulation of stress-inducible factors, leading to natural killer (NK) cell activation and thus slower tumor growth (Gourzi et al., 2006). AID expression also correlates with the induction of aberrant SHM that might contribute to B cell transformation and tumorigenesis (Machida et al., 2005; Epeldegui et al., 2007).

\section{APOBEC3s AND ANTIVIRAL IMMUNITY}

A3G was the first member of APOBEC family to be assigned a role in antiviral immunity by demonstration of its activity against HIV infectivity (Sheehy et al., 2002). Since then, it has been demonstrated that human A3 cytidine deaminases affect the replication of a variety of viruses (Chiu and Greene, 2008) and impact the activation of adaptive immunity (Casartelli et al., 2010). A3G restricts the replication of retroviruses such as HIV, Foamy virus (FV; Delebecque et al., 2006), human T-cell leukemia virus type-1 (HTLV-1; Mahieux etal., 2005) as well as DNA viruses such as HBV (Turelli et al., 2004; Suspene et al., 2005) and also affects endogenous retroviruses (Esnault et al., 2005). $\mathrm{A} 3 \mathrm{~A}, \mathrm{~A} 3 \mathrm{C}$, and $\mathrm{A} 3 \mathrm{H}$ deaminate human papillomavirus (HPV) genomes (Vartanian et al., 2008) and A3C acts on herpes viruses [e.g., herpes simplex-1 (HSV-1) and EBV viruses (Suspene et al., 2011b)]. Human A3G also acts on viruses infecting rodents (MLV) or avian species (Rous sarcoma virus and alpharetroviruses). A3 family members can play redundant roles in antiviral immunity (Albin and Harris, 2010). For instance, A3G and A3F restrict HIV and like A3C, A3G also acts on herpes viruses, although to a lesser extent (Suspene et al., 2011b). Intrinsic specificities of A3 proteins, but also their tissue distribution and cellular expression levels most likely determine the impact of each A3 family member on viral replication and on the activation of antiviral immunity.

\section{INTRINSIC ANTIVIRAL FUNCTION OF A3s}

The characterization of mutant HIV defective for the accessory protein Vif led to the discovery of A3G. Vif is essential for HIV1 replication in a variety of cells including primary human $\mathrm{T}$ cells, monocytes, macrophages, DC and lymphoid $\mathrm{T}$ cell lines such as CEM, HUT78, also called "non-permissive" cells. However, Vif is dispensable in "permissive" T cell lines such as CEM-SS (a variant of CEM), Jurkat and supT1 cells [see for an in depth review (Henriet et al., 2009)]. A subtractive cDNA library screen using CEM and CEM-SS T cell lines - led to the identification of human A3G that is strongly expressed by non-permissive CEM-SS cells (Sheehy et al., 2002). In non-permissive cells, A3G is incorporated into budding virions and acts on HIV replication in a post-fusion event in newly infected cells (Figure 1). Transfection of A3G in permissive cells leads to abrogated replication of Vifdeficient HIV (HIV $\Delta$ Vif) (Sheehy et al., 2002) and sequencing of HIV $\triangle$ VifDNA revealed a hypermutated pattern with enriched G to A transitions (Lecossier et al., 2003), strongly suggesting that A3G deaminase activity is required for the restriction of HIV replication (Zhang etal., 2003). It is now established that Vif counteracts the antiviral functions of A3G and other A3 family members such as $\mathrm{A} 3 \mathrm{~F}$ and a certain allele of $\mathrm{A} 3 \mathrm{H}$ (Henriet et al., 2009). The action of Vif on A3s has been extensively reviewed (Henriet et al., 2009), but in sum, in infected cells, Vif targets A3G for proteasomal degradation, reducing the amount of A3G incorporated into budding virions (Figure 1). Indeed, as a postfusion event, A3G catalyzes cytosine to uracil deamination on the nascent minus DNA strand of the HIV reverse transcribed genome (Harris et al., 2003; Mangeat et al., 2003; Yu et al., 2004). The presence of uracil on the minus strand of HIV DNA might target HIV DNA for degradation by the cellular DNA repair machinery thus reducing viral replication (Mariani et al., 2003). As exemplified by the existence of hyper-edited sequences retrieved from HIV proviruses in vivo (Kieffer et al., 2005), the action of Vif on A3G incorporation/degradation is not absolute and deaminations also lead to G to A transitions in HIV DNA (Harris et al., 2003; Lecossier et al., 2003; Mangeat et al., 2003; Yu et al., 2004). Editing patterns are dominated by GG to AG hypermutations leading to a high frequency of amino acid substitutions and to the introduction of premature STOP codons (Vartanian et al., 1991). These crippled proviruses express aberrant (i.e., misfolded or truncated) viral proteins that are unable to produce infectious particles (Simm et al., 1995).

Shortly after the discovery of A3G, A3F was shown to restrict $\mathrm{HIV}$ replication. $\mathrm{A} 3 \mathrm{G}$ and $\mathrm{A} 3 \mathrm{~F}$ editing is not random. $\mathrm{A} 3 \mathrm{G}$ and $\mathrm{A} 3 \mathrm{~F}$ preferentially introduce mutations in TGG or TGA sequences, respectively. There is a lack of consensus on the ability of other A3 family members to edit HIV [see for a review (Albin and Harris, 2010)]. For instance, over-expression of A3B and A3DE exerts anti-HIV activity in a single cycle assay but insignificant antiviral activity in a spreading infection system (Hache et al., 2008). A3D, F, G, and $\mathrm{H}$ but not A3B, C, and DE restrict infection of human $\mathrm{CD} 4+\mathrm{T}$ lymphocytes by Vif-deficient viruses (Hultquist et al., 2011). A3DE restricts HIV replication in macrophages but to a lower extent than A3G (Chaipan et al., 2013). In myeloid cells, APOBEC3A blocks early steps of reverse transcription but acts when expressed in the target cell of infection (Berger et al., 2011).

There is a general agreement that cytidine deamination plays an important role in the capacity of A3s to restrict viral replication (Schumacher et al., 2008; Browne et al., 2009). However, several reports also suggest that $\mathrm{A} 3 \mathrm{G}$ and $\mathrm{A} 3 \mathrm{~F}$ restrict viral replication to a significant extent through deaminase-independent mechanisms (Newman et al., 2005). A3G and A3F affect reverse transcription priming and extension (Mangeat et al., 2003; Mariani et al., 2003; Guo et al., 2006; Anderson and Hope, 2008; Malim, 2009; Wang et al., 2012; Gillick et al., 2013) and HIV DNA integration into the host genome (Luo et al., 2007; Mbisa et al., 2007; Vetter and D’Aquila, 2009). As proposed by Henriet et al. (2009) interference of $\mathrm{A} 3 \mathrm{G}$ and $\mathrm{A} 3 \mathrm{~F}$ with the viral core assembly might be responsible for these deaminase-independent impairments of HIV replication. 


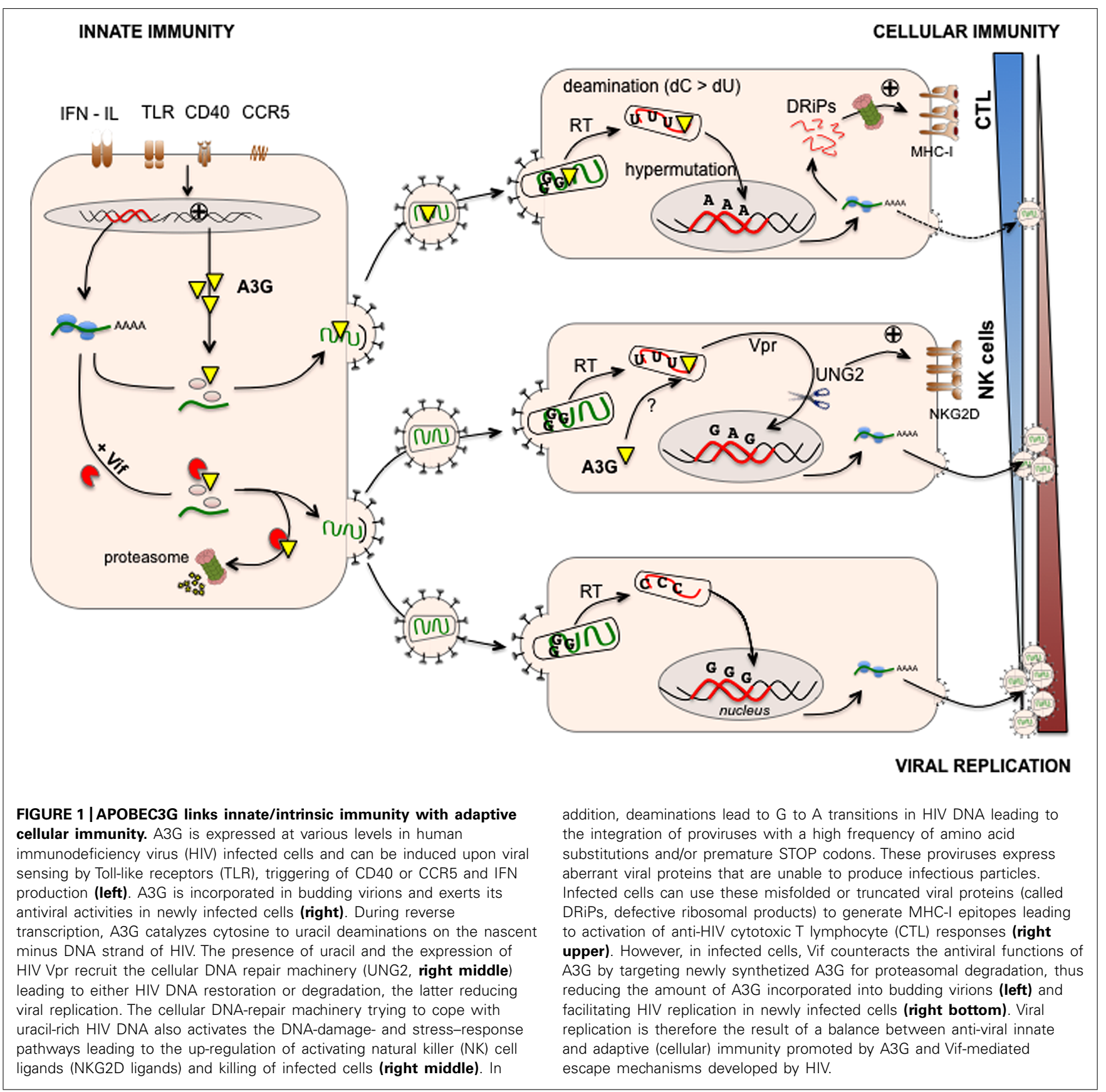

The balance of editing and non-editing-dependent effects of A3G and $\mathrm{A} 3 \mathrm{~F}$ varies depending on the experimental system and might be affected by their cellular expression levels (Miyagi et al., 2007; Knoepfel et al., 2008; Browne et al., 2009).

\section{INDUCTION OF A3 EXPRESSION}

In humans, A3s are not only expressed in a variety of tissues, but their expression is also induced by mediators of inflammation, possibly reflecting their role as a first line of defense against invading viruses (Figure 1). IFN- $\alpha$ was reported to enhance A3G and $\mathrm{A} 3 \mathrm{~A}$ expression in monocytes and macrophages. IFN $-\gamma$ and $-\beta$ also induce A3G up-regulation in macrophages (Sarkis et al., 2006;

Peng et al., 2007; Stopak et al., 2007; Koning et al., 2009; Refsland et al., 2010; Berger et al., 2011). IFN- $\alpha$ secreted by plasmacytoid dendritic cells ( $\mathrm{pDC}$ ) enhances the expression of $\mathrm{A} 3 \mathrm{~A}, \mathrm{A3C}, \mathrm{A} 3 \mathrm{G}$, and $\mathrm{A} 3 \mathrm{~F}$ within $\mathrm{pDC}$, indicating that $\mathrm{pDC}$ might be armed against viral infection by an autocrine IFN- $\alpha$ loop (Wang et al., 2008). Pathogen sensors such as Toll-like receptors (TLR) also influence A3 gene expression. TLR-3 stimulation by the double stranded RNA analog [poly(I:C)] induces type I IFN responses in DC and subsequent A3G expression (Trapp et al., 2009). Overall, the induction of DC maturation using stimuli such as LPS (a TLR-4 ligand), CCR5 and CD40 ligands correlates with the up-regulation of A3G (Pion etal., 2006; Pido-Lopez et al., 2007; Stopak et al., 
2007). The effect of IFN- $\alpha$ on A3 expression in primary CD4+ $\mathrm{T}$ cells is controversial, but in most reports no induction was observed (Rose et al., 2005; Chen et al., 2006; Sarkis et al., 2006; Stopak etal., 2007; Ying et al., 2007; Koning et al., 2009; Refsland et al., 2010). In contrast, IL-2, IL-7, IL-15, and IL-27 and mitogens such as phytohemagglutinin (PHA) and phorbol myristate acetate (PMA) induced modest and strong activation of A3G expression, respectively, (Stopak et al., 2007). Combined with IL2, PHA induces expression of all A3s except A3A (Greenwell-Wild et al., 2009; Koning et al., 2009; Refsland et al., 2010). Triggering of the $\mathrm{T}$ cell receptor $(\mathrm{TcR})$ also induces $\mathrm{A} 3 \mathrm{G}$ expression in effector memory $\mathrm{T}$ cells and interferes with HIV replication in vitro (Pido-Lopez et al., 2009).

The induction of A3 expression is not limited to immune cells. IFN- $\alpha$ secretion, for instance, can induce A3G, A3F, and A3B expression in hepatocytes (Bonvin et al., 2006; Sarkis et al., 2006; Tanaka et al., 2006). In contrast, other factors reduce A3 protein expression. The nerve growth factor (NGF), an essential factor for survival and activation of monocytes/macrophages, is released by HIV infected macrophages and dampens the synthesis of $A 3 G$, overriding the IFN- $\gamma$-induced upregulation of $A 3 G$ (Souza et al., 2011).

Overall, the transcriptional regulation of A3 genes seems to play a major role in A3-dependent defenses against viruses. Remarkably, following mucosal immunization of nonhuman primates, two studies reported the up-regulation of A3G in CCR5+ CD4+ memory T cells (Wang et al., 2009) as well as in mucosal DC and CD14+ cells (Sui et al., 2010), all potential cellular targets of HIV replication. A3G mRNA upregulation was maintained over several weeks after immunization and upon challenge with SIV, and correlated inversely with viral loads and positively with a better preservation of CD4+ T cells in the gut (Sui et al., 2010). These studies strongly suggest that A3G provides an antiviral effect in vivo. They also demonstrate that mucosal immunization triggers an innate signature that promotes adaptive immune responses. The exact mechanism underlying vaccine-induced A3G expresssion with protection from SIV infection is not clear. As observed in the murine model of Friend retrovirus (FV) infection (Santiago et al., 2010), by limiting early viral replication, A3G might delay virus-induced immune dysfunction and thus might favor the establishment of humoral [e.g., generation of FV-neutralizing antibodies (Santiago et al., 2010)] and cellular immunity.

\section{A ROLE OF A3G IN THE ACTIVATION OF CELLULAR AND ADAPTIVE IMMUNITY}

There is growing evidence that A3G bridges intrinsic and cellular immunity as is the case with AID, that shapes the $\mathrm{Ab}$ repertoire, blocks virus-induced cancer by inducing cell cycle arrest and activates NK cells (Gourzi et al., 2006). A3G has been implicated in enhancing NK-cell killing of HIV-infected T cells (Norman etal., 2011). This process requires A3G-editing of HIV DNA (Norman etal., 2011). In this study, the authors propose that the cellular DNA-repair machinery activates DNAdamage- and stress-response pathways in response to uraciledited HIV DNA, leading to the up-regulation of activating NK cell ligands (NKG2D ligands) and killing of HIV infected cells. The authors also implicate the HIV Vpr protein and its capacity to recruit the DNA-repair machinery as a key factor in NKG2D ligand expression. In contrast, HIV Vif counteracts the action of $\mathrm{A} 3 \mathrm{G}$ and the $\mathrm{NK}$ cell-mediated elimination of HIV-infected cells (Norman et al., 2011). Interestingly, in the work of Norman etal. (2011), cytoplasmic A3G (expressed by the target cell) seems responsible for HIV editing and thus NK cell recognition. Cytoplasmic $\mathrm{A} 3 \mathrm{G}$ has been shown to impact HIV genome integration but has not been assigned a role in HIV genome editing, to our knowledge (Vetter and D'Aquila, 2009). Whether the accumulation of unintegrated HIV genomes or the editing of HIV genomes per se might be responsible for the induction of stress responses and thus NK cell recognition remains to be clarified (Norman et al., 2011). Nonetheless, this study suggests that A3G antiviral functions allow triggering of danger signals that, in turn, activate effectors of cellular immunity.

A3G-mediated editing also contributes to the activation of effectors of adaptive immunity (Casartelli et al., 2010), namely, CD8+ cytotoxic T cells (CTLs). CTLs, whose function is critical in the control of HIV infection, are triggered by viral peptides presented by MHC class-I molecules on the surface of infected cells. These antigenic peptides originate from proteasomal degradation of native viral proteins and of defective/abortive proteins generated in the course of translation (Yewdell and Nicchitta, 2006). We made the assumption that hyper-edited proviruses that express aberrant - misfolded or truncated - viral proteins might represent a source of HIV antigens. We demonstrated that A3G enhances cytotoxic T lymphocyte (CTL) recognition of HIV-infected cells (Casartelli et al., 2010). This process requires A3G-editing of HIV DNA as editing-deficient A3G mutants failed to promote CTL activation. Mimicking A3G-editing, we also showed that truncated HIV proteins represent a major source of HIV antigen for CTL activation (Casartelli et al., 2010). However, and as expected, Vif as well as Nef (that down-regulated MHC-I expression) counteracts the action of $A 3 G$ in antigen generation. Therefore, recognition of HIV-infected cells by CTLs results from a balance between the efficacy of antigen generation enhanced by A3G editing and the immune-escape mechanisms mediated by the virus. Overall, these studies demonstrate that A3G-mediated viral restriction contributes to the immunogenicity of HIV-infected cells and to NK cell as well as CTL activation, thus linking innate and adaptive immunity (Figure 1). Whether other APOBEC3 family members enhance NK cell and CTL activation remains to be determined.

\section{IN VIVO INTERACTIONS OF APOBEC3s AND HIV-1 A3s AND CORRELATES OF DISEASE PROGRESSION}

Accumulating evidence suggests that A3s play an important role in limiting viral replication in vivo. APOBEC3 genes have been subject to strong positive selection throughout the history of primate evolution (Sawyer et al., 2004). In persistent HBV infection, A3 polymorphisms seem to impact liver disease progression and viral loads (Ezzikouri et al., 2013). In the course of HIV infection, A3G plays a critical role in limiting the viral reservoir. A major barrier to an effective cure of HIV infection is the maintenance of a latent viral reservoir in the memory CD4 $\mathrm{T}$ cell compartment within HIV-infected, successfully treated 
(ST) individuals (Chomont etal., 2009). Examining the state of the latent proviruses in these cells from ST subjects, several studies have established that approximately 30\% of HIV proviruses that can not be reactivated in vitro carry the hallmark of A3G editing (Ho etal., 2013). Thus, in vivo, A3G plays a significant role in rendering the persistent viral reservoir defective, inactive, or "non-inducible." However, whether A3G antiviral functions play a critical role in HIV progression is less clear (Albin and Harris, 2010). Analyzing the mutation patterns of proviral sequences isolated from various cohorts, several studies showed a correlation between hypermutation mediated by either A3G or A3F and reduced viral loads (Pace et al., 2006; Vazquez-Perez etal., 2009; Kourteva etal., 2012) or increased CD4 counts (Land et al., 2008). Consistent with these observations, proviral sequences from HIV-infected longterm non-progressors (LTNP) or viral controllers (elite controllers) seem to harbor an elevated level of hypermutation compared to antiretroviral therapy (ART)-treated or naïve noncontrollers (Kourteva et al., 2012; Eyzaguirre et al., 2013). In contrast, others observed no correlation between hypermutation with markers of disease progression (Piantadosi et al., 2009; De Maio etal., 2012) nor with the clinical status such as being elite controllers (Gandhi et al., 2008). These contrasting results might be due to technical issues or the size of the cohorts studied.

However, owing to the editing-independent antiviral activities of A3s, other studies analyzed the association between A3G or A3F expression levels (mostly at the mRNA level) and markers of disease progression. But, again, there is no clear-cut answer. Some studies observed that the mRNA levels of A3G correlate positively with CD4 cell counts (Jin et al., 2005; Vazquez-Perez et al., 2009; Zhao et al., 2010) and inversely with viremia (Jin et al., 2005; Zhao et al., 2010; Kourteva et al., 2012) or the viral set point (that is predictive of disease progression; Ulenga et al., 2008). In addition, exposed uninfected individuals showed greater A3G mRNA levels (Biasin et al., 2007; Vazquez-Perez et al., 2009) and controllers with high A3G protein expression in CD4 T cells seem to harbor fewer HIV proviruses (De Pasquale et al., 2013). However, others observed no correlation between mRNA expression levels of either $\mathrm{A} 3 \mathrm{G}$ or A3F and markers of disease progression (Cho et al., 2006; Amoedo et al., 2011). Also, during primary infection no association between $\mathrm{A} 3 \mathrm{G}$ expression and viral loads was observed (Reddy et al., 2010) and others did not find greater A3G mRNA levels in exposed uninfected individuals (Mous et al., 2012). Larger cohort studies analyzing side-by-side hypermutation patterns and expression levels of all A3 family members might help in establishing a correlation with clinical parameters.

However, variants of A3 at the genetic levels might also account for limiting disease progression. In a pioneering study, An et al (An et al., 2004) identified a variety of A3G polymorphisms within introns and exons that correlate with clinical parameters. A3G H186R identified in this study was shown in various cohort studies to correlate with disease progression (An et al., 2004; Reddy et al., 2010; Singh et al., 2013). The variant H186R of A3G is also associated with low CD4 counts (Bunupuradah et al., 2012) and a polymorphism within an A3G intron (C40693T) was shown to correlate with increased risk of infection (Valcke et al., 2006).
Other members of the APOBEC3 family present common polymorphisms such as $\mathrm{A} 3 \mathrm{H}$ and $\mathrm{A} 3 \mathrm{~B}$. In contrast to $\mathrm{A} 3 \mathrm{G}, \mathrm{A} 3 \mathrm{H}$ anti-HIV activity is strongly influenced by its polymorphisms (Ooms et al., 2013) with some specific alleles associated with lower viremia (Gourraud et al., 2011). A3B is deleted in $~ 20 \%$ of the world's population. An early study based on a large number of U.S. patients showed that a homozygous deletion of $\mathrm{A} 3 \mathrm{~B}$ was associated with increased susceptibility to HIV acquisition and progression to AIDS (An et al., 2009). However, a more recent study on Japanese individuals did not observe such a correlation (Imahashi et al., 2014).

Whether A3 family members influence viral transmission and disease progression remains an open question. In addition, the underlying mechanisms are not clear, such as whether A3G H186R and C40693T differentially impact HIV replication, and to date, this has not been experimentally demonstrated.

\section{A3-MEDIATED EDITING AND VIRAL DIVERSIFICATION/ADAPTATION}

A3 antiviral activities, and, in particular, editing, might also facilitate HIV survival by introducing sub-lethal mutations that, in turn, favor HIV diversification and adaptation to ART and/or immune responses. The action of Vif on A3 degradation is not absolute thus allowing A3 incorporation and subsequent sublethal editing (Sadler et al., 2010). Evidence of this phenomenon was provided by the demonstration that a Vif allele carrying the $\mathrm{K} 22 \mathrm{H}$ mutation, less effective in counteracting A3-mediated editing, was prevalent in a cohort of ART-treated patients experiencing virological failure (Fourati etal., 2010). In this study, several drug resistance mutations in reverse transcriptase (RT) and in the protease, were significantly more common in patients harboring elevated levels of K22H-mutated viruses (Fourati et al., 2010). The expression of $\mathrm{K} 22 \mathrm{H}-\mathrm{Vif}$ might favor adaptation to antiviral drugs by allowing residual A3-mediated deamination and introduction of mutations into HIV genome. A parallel might be drawn here with hypermutator strains of bacteria that adapt more rapidly to antibiotic. These hypermutator strains of bacteria have mutations in genes affecting DNA repair and replication fidelity and exhibit elevated mutation rates (Woodford and Ellington, 2007). Cytidine deamination might directly promote mutations that generate resistance to drugs. For example, the common M184V mutation of RT that causes resistance to 3TC is located in an A3G editing hotspot and is produced in vitro by $\mathrm{A} 3 \mathrm{G}$ during $\mathrm{HIV}$ replication (Mulder et al., 2008; Kim et al., 2010). A3G-mediated sub-lethal editing might also favor mutations within sequences encoding HIV CTL epitopes thus allowing the virus to escape CTL-recognition (Wood et al., 2009; Monajemi etal., 2014). In contrast, cytidine deamination outside HIV CTL epitopes (especially downstream of the epitope) might favor the expression of unstable aberrant or truncated HIV proteins and thus HIV-specific CTL activation (Casartelli et al., 2010).

On the other hand, A3G-editing at physiological levels might be simply lethal to HIV. Armitage et al. (2012) showed, in an in vitro study, that even a single $\mathrm{A} 3 \mathrm{G}$ molecule within one HIV particle is likely to cause extensive and inactivating levels of HIV hypermutation (Armitage et al., 2012). The authors 
suggest that A3-mediated hypermutation might be a discrete "all or nothing" phenomenon (Armitage et al., 2012). The overall impact of A3-mediated hypermutation on HIV survival and adaptation might also vary depending on the anatomical site (Fourati et al., 2014).

\section{CONCLUDING REMARKS}

The AID-APOBEC family members evolved from a family of cytidine deaminases to fight viral infection. They constitute an important arm of innate immunity by restricting replication and spread of a plethora of viral infections. Although establishing correlates of disease progression with hypermutation or expression levels as a surrogate of APOBEC antiviral functions has proven to be complex in HIV infection, in vivo defective proviral sequences clearly bear the hallmark of APOBEC editing. AID-APOBEC family members also participate in long-term adaptive immunity to viral infections. AID is critical for the generation of B cells that secrete high affinity Abs with various effector functions. A3G contributes in activating NK cell and CTL responses leading to the elimination of HIV-infected cells. Remarkably, the expression levels of AID-APOBEC family members are increased upon the sensing of infection and a tight regulation is required to avoid deleterious editing of host genomes.

Manipulating AID-APOBECs with drugs might constitute promising approaches to fight infections. Strategies have been proposed to increase A3 expression to favor encapsidation within viral particles thus overriding the antagonistic activity of Vif and controlling HIV-1 infection [reviewed in (Albin and Harris, 2010)]. The antiviral properties of Vif inhibitors are currently being evaluated (Ali et al., 2012). A3G expression can be manipulated either by limiting its proteasomal degradation (Ejima et al., 2011), or exacerbated to supraphysiologic levels. Treatment of $\mathrm{HIV} / \mathrm{HCV}$ co-infected patients with IFN- $\alpha$, for instance, increases mRNA expression of $\mathrm{A} 3 \mathrm{G} / \mathrm{F}$ and correlates with the degree of HIV hypermutation (Pillai et al., 2012). Upon vaccination, A3 expresssion can also be induced promoting adaptive immune responses (Wang etal., 2009; Sui et al., 2010). Taken together, these findings further highlight the complex and intriguing interactions of AID-APOBEC family members with the immune system.

\section{ACKNOWLEDGMENTS}

This work was supported by grants from the Agence National de la Recherche sur le Sida et les Hépatites (ANRS), Sidaction and Pierre et Marie Curie University (Paris-06). Shannon Murray was supported by a post-doctoral grant from the ANRS. Sylvain Cardinaud was supported by a post-doctoral grant from Sidaction and the CutHIVac European consortium (EU FP7).

\section{REFERENCES}

Albin, J. S., and Harris, R. S. (2010). Interactions of host APOBEC3 restriction factors with HIV-1 in vivo: implications for therapeutics. Expert Rev. Mol. Med. 12:e4. doi: 10.1017/S1462399409001343

Ali, A., Wang, J., Nathans, R. S., Cao, H., Sharova, N., Stevenson, M., et al. (2012). Synthesis and structure-activity relationship studies of HIV-1 virion infectivity factor (Vif) inhibitors that block viral replication. ChemMedChem 7, 1217-1229. doi: $10.1002 / \mathrm{cmdc} .201200079$

Amoedo, N. D., Afonso, A. O., Cunha, S. M., Oliveira, R. H., Machado, E. S., and Soares, M. A. (2011). Expression of APOBEC3G/3F and G-to-A hypermutation levels in HIV-1-infected children with different profiles of disease progression. PLoS ONE 6:e24118. doi: 10.1371/journal.pone.0024118

An, P., Bleiber, G., Duggal, P., Nelson, G., May, M., Mangeat, B., et al. (2004). APOBEC3G genetic variants and their influence on the progression to AIDS. J. Virol. 78, 11070-11076. doi: 10.1128/JVI.78.20.11070-11076.2004

An, P., Johnson, R., Phair, J., Kirk, G. D., Yu, X. F., Donfield, S., et al. (2009). APOBEC3B deletion and risk of HIV-1 acquisition. J. Infect. Dis. 200, 1054-1058. doi: $10.1086 / 605644$

Anderson, J. L., and Hope, T. J. (2008). APOBEC3G restricts early HIV1 replication in the cytoplasm of target cells. Virology 375, 1-12. doi: 10.1016/j.virol.2008.01.042

Armitage, A. E., Deforche, K., Chang, C. H., Wee, E., Kramer, B., Welch, J. J., et al. (2012). APOBEC3G-induced hypermutation of human immunodeficiency virus type-1 is typically a discrete "all or nothing" phenomenon. PLoS Genet. 8:e1002550. doi: 10.1371/journal.pgen.1002550

Basu, U., Chaudhuri, J., Alpert, C., Dutt, S., Ranganath, S., Li, G., et al. (2005). The AID antibody diversification enzyme is regulated by protein kinase a phosphorylation. Nature 438, 508-511. doi: 10.1038/nature04255

Basu, U., Meng, F. L., Keim, C., Grinstein, V., Pefanis, E., Eccleston, J., et al. (2011). The RNA exosome targets the AID cytidine deaminase to both strands of transcribed duplex DNA substrates. Cell 144, 353-363. doi: 10.1016/j.cell.2011. 01.001

Bekerman, E., Jeon, D., Ardolino, M., and Coscoy, L. (2013). A role for host activation-induced cytidine deaminase in innate immune defense against KSHV. PLoS Pathog. 9:e1003748. doi: 10.1371/journal.ppat.1003748

Berger, G., Durand, S., Fargier, G., Nguyen, X. N., Cordeil, S., Bouaziz, S., et al. (2011). APOBEC3A is a specific inhibitor of the early phases of HIV-1 infection in myeloid cells. PLoS Pathog. 7:e1002221. doi: 10.1371/journal.ppat. 1002221

Biasin, M., Piacentini, L., Lo Caputo, S., Kanari, Y., Magri, G., Trabattoni, D., et al. (2007). Apolipoprotein B mRNA-editing enzyme, catalytic polypeptide-like 3G: a possible role in the resistance to HIV of HIV-exposed seronegative individuals. J. Infect. Dis. 195, 960-964. doi: 10.1086/511988

Bishop, K. N., Holmes, R. K., Sheehy, A. M., Davidson, N. O., Cho, S. J., and Malim, M. H. (2004a). Cytidine deamination of retroviral DNA by diverse APOBEC proteins. Curr. Biol. 14, 1392-1396. doi: 10.1016/j.cub.2004.06.057

Bishop, K. N., Holmes, R. K., Sheehy, A. M., and Malim, M. H. (2004b). APOBECmediated editing of viral RNA. Science 305, 645. doi: 10.1126/science.1100658

Bonvin, M., Achermann, F., Greeve, I., Stroka, D., Keogh, A., Inderbitzin, D., et al. (2006). Interferon-inducible expression of APOBEC3 editing enzymes in human hepatocytes and inhibition of hepatitis B virus replication. Hepatology 43 , 1364-1374. doi: 10.1002/hep.21187

Browne, E. P., Allers, C., and Landau, N. R. (2009). Restriction of HIV-1 by APOBEC3G is cytidine deaminase-dependent. Virology 387, 313-321. doi: 10.1016/j.virol.2009.02.026

Bunupuradah, T., Imahashi, M., Iampornsin, T., Matsuoka, K., Iwatani, Y., Puthanakit, T., et al. (2012). Association of APOBEC3G genotypes and CD4 decline in Thai and Cambodian HIV-infected children with moderate immune deficiency. AIDS Res. Ther. 9:34. doi: 10.1186/1742-6405-9-34

Casartelli, N., Guivel-Benhassine, F., Bouziat, R., Brandler, S., Schwartz, O., and Moris, A. (2010). The antiviral factor APOBEC3G improves CTL recognition of cultured HIV-infected T cells. J. Exp. Med. 207, 39-49. doi: 10.1084/jem. 20091933 Chaipan, C., Smith, J. L., Hu, W. S., and Pathak, V. K. (2013). APOBEC3G restricts HIV-1 to a greater extent than APOBEC3F and APOBEC3DE in human primary CD4+ T cells and macrophages. J. Virol. 87, 444-453. doi: 10.1128/JVI. 00676-612

Chen, K., Huang, J., Zhang, C., Huang, S., Nunnari, G., Wang, F. X., et al. (2006). Alpha interferon potently enhances the anti-human immunodeficiency virus type 1 activity of APOBEC3G in resting primary CD4 T cells. J. Virol. 80, 7645-7657. doi: 10.1128/JVI.00206-06

Chiu, Y. L., and Greene, W. C. (2008). The APOBEC3 cytidine deaminases: an innate defensive network opposing exogenous retroviruses and endogenous retroelements. Аnпu. Rev. Immunol. 26, 317-353. doi: 10.1146/annurev.immunol.26.021607.090350

Cho, S. J., Drechsler, H., Burke, R. C., Arens, M. Q., Powderly, W., and Davidson, N. O. (2006). APOBEC3F and APOBEC3G mRNA levels do not correlate with human immunodeficiency virus type 1 plasma viremia or CD4+ T-cell count. $J$. Virol. 80, 2069-2072. doi: 10.1128/JVI.80.4.2069-2072.2006 
Chomont, N., El-Far, M., Ancuta, P., Trautmann, L., Procopio, F. A., Yassine-Diab, B., et al. (2009). HIV reservoir size and persistence are driven by T cell survival and homeostatic proliferation. Nat. Med. 15, 893-900. doi: 10.1038/nm.1972

Conticello, S. G. (2008). The AID/APOBEC family of nucleic acid mutators. Genome Biol. 9, 229. doi: 10.1186/gb-2008-9-6-229

Conticello, S. G., Langlois, M. A., Yang, Z., and Neuberger, M. S. (2007). DNA deamination in immunity: AID in the context of its APOBEC relatives. $A d v$. Immunol. 94, 37-73. doi: 10.1016/S0065-2776(06)94002-94004

Conticello, S. G., Thomas, C. J., Petersen-Mahrt, S. K., and Neuberger, M. S. (2005). Evolution of the AID/APOBEC family of polynucleotide (deoxy)cytidine deaminases. Mol. Biol. Evol. 22, 367-377. doi: 10.1093/molbev/msi026

Dang, Y., Wang, X., Esselman, W. J., and Zheng, Y. H. (2006). Identification of APOBEC3DE as another antiretroviral factor from the human APOBEC family. J. Virol. 80, 10522-10533. doi: 10.1128/JVI.01123-06

De Maio, F. A., Rocco, C. A., Aulicino, P. C., Bologna, R., Mangano, A., and Sen, L. (2012). APOBEC3-mediated editing in HIV type 1 from pediatric patients and its association with APOBEC3G/CUL5 polymorphisms and Vif variability. AIDS Res. Hum. Retroviruses 28, 619-627. doi: 10.1089/AID.2011.0291

De Pasquale, M., Kourteva, Y., Allos, T., and D'aquila, R. T. (2013). Lower HIV provirus levels are associated with more APOBEC3G protein in blood resting memory CD4+ T lymphocytes of controllers in vivo. PLoS ONE 8:e76002. doi: 10.1371/journal.pone.0076002

Delebecque, F., Suspene, R., Calattini, S., Casartelli, N., Saib, A., Froment, A., et al. (2006). Restriction of foamy viruses by APOBEC cytidine deaminases. J. Virol. 80, 605-614. doi: 10.1128/JVI.80.2.605-614.2006

Desimmie, B. A., Delviks-Frankenberrry, K. A., Burdick, R. C., Qi, D., Izumi, T., and Pathak, V. K. (2014). Multiple APOBEC3 restriction factors for HIV-1 and one Vif to rule them all. J. Mol. Biol. 426, 1220-1245. doi: 10.1016/j.jmb.2013.10.033

Ejima, T., Hirota, M., Mizukami, T., Otsuka, M., and Fujita, M. (2011). An anti-HIV1 compound that increases steady-state expression of apoplipoprotein B mRNAediting enzyme-catalytic polypeptide-like 3G. Int. J. Mol. Med. 28, 613-616. doi: 10.3892/ijmm.2011.737

Epeldegui, M., Hung, Y. P., Mcquay, A., Ambinder, R. F., and Martinez-Maza, O. (2007). Infection of human B cells with Epstein-Barr virus results in the expression of somatic hypermutation-inducing molecules and in the accrual of oncogene mutations. Mol. Immunol. 44, 934-942. doi: 10.1016/j.molimm.2006.03.018

Esnault, C., Heidmann, O., Delebecque, F., Dewannieux, M., Ribet, D., Hance, A. J., et al. (2005). APOBEC3G cytidine deaminase inhibits retrotransposition of endogenous retroviruses. Nature 433, 430-433. doi: 10.1038/nature03238

Etard, C., Roostalu, U., and Strahle, U. (2010). Lack of Apobec2-related proteins causes a dystrophic muscle phenotype in zebrafish embryos. J. Cell Biol. 189, 527-539. doi: 10.1083/jcb.200912125

Eyzaguirre, L. M., Charurat, M., Redfield, R. R., Blattner, W. A., Carr, J. K., and Sajadi, M. M. (2013). Elevated hypermutation levels in HIV-1 natural viral suppressors. Virology 443, 306-312. doi: 10.1016/j.virol.2013.05.019

Ezzikouri, S., Kitab, B., Rebbani, K., Marchio, A., Wain-Hobson, S., Dejean, A. et al. (2013). Polymorphic APOBEC3 modulates chronic hepatitis B in Moroccan population. J. Viral Hepat. 20, 678-686. doi: 10.1111/jvh.12042

Fourati, S., Lambert-Niclot, S., Soulie, C., Wirden, M., Malet, I., Valantin, M. A., et al. (2014). Differential impact of APOBEC3-driven mutagenesis on HIV evolution in diverse anatomical compartments. AIDS 28, 487-491. doi: 10.1097/QAD.0000000000000182

Fourati, S., Malet, I., Binka, M., Boukobza, S., Wirden, M., Sayon, S., et al. (2010). Partially active HIV-1 Vif alleles facilitate viral escape from specific antiretrovirals. AIDS 24, 2313-2321. doi: 10.1097/QAD.0b013e32833e515a

Fritz, E. L., and Papavasiliou, F. N. (2010). Cytidine deaminases: AIDing DNA demethylation? Genes Dev. 24, 2107-2114. doi: 10.1101/gad.1963010

Gallois-Montbrun, S., Holmes, R. K., Swanson, C. M., Fernandez-Ocana, M., Byers, H. L., Ward, M. A., et al. (2008). Comparison of cellular ribonucleoprotein complexes associated with the APOBEC3F and APOBEC3G antiviral proteins. J. Virol. 82, 5636-5642. doi: 10.1128/JVI.00287-08

Gandhi, S. K., Siliciano, J. D., Bailey, J. R., Siliciano, R. F., and Blankson, J. N. (2008). Role of APOBEC3G/F-mediated hypermutation in the control of human immunodeficiency virus type 1 in elite suppressors. J. Virol. 82, 3125-3130. doi: 10.1128/JVI.01533-07

Gillick, K., Pollpeter, D., Phalora, P., Kim, E. Y., Wolinsky, S. M., and Malim, M. H. (2013). Suppression of HIV-1 infection by APOBEC3 proteins in primary human CD4(+) $\mathrm{T}$ cells is associated with inhibition of processive reverse transcription as well as excessive cytidine deamination. J. Virol. 87, 1508-1517. doi: 10.1128/JVI.02587-12

Gonzalez, M. C., Suspene, R., Henry, M., Guetard, D., Wain-Hobson, S., and Vartanian, J. P. (2009). Human APOBEC1 cytidine deaminase edits HBV DNA. Retrovirology 6, 96. doi: 10.1186/1742-4690-6-96

Gourraud, P. A., Karaouni, A., Woo, J. M., Schmidt, T., Oksenberg, J. R., Hecht, F. M., et al. (2011). APOBEC3H haplotypes and HIV-1 pro-viral vif DNA sequence diversity in early untreated human immunodeficiency virus-1 infection. Hum. Immunol. 72, 207-212. doi: 10.1016/j.humimm.2010.12.008

Gourzi, P., Leonova, T., and Papavasiliou, F. N. (2006). A role for activation-induced cytidine deaminase in the host response against a transforming retrovirus. Immunity 24, 779-786. doi: 10.1016/j.immuni.2006.03.021

Greenwell-Wild, T., Vazquez, N., Jin, W., Rangel, Z., Munson, P. J., and Wahl, S. M. (2009). Interleukin-27 inhibition of HIV-1 involves an intermediate induction of type I interferon. Blood 114, 1864-1874. doi: 10.1182/blood-2009-03-211540

Greeve, J., Altkemper, I., Dieterich, J. H., Greten, H., and Windler, E. (1993). Apolipoprotein B mRNA editing in 12 different mammalian species: hepatic expression is reflected in low concentrations of apoB-containing plasma lipoproteins. J. Lipid Res. 34, 1367-1383.

Guo, F., Cen, S., Niu, M., Saadatmand, J., and Kleiman, L. (2006). Inhibition of formula-primed reverse transcription by human APOBEC3G during human immunodeficiency virus type 1 replication. J. Virol. 80, 11710-11722. doi: 10.1128/JVI.01038-06

Hache, G., Shindo, K., Albin, J. S., and Harris, R. S. (2008). Evolution of HIV1 isolates that use a novel Vif-independent mechanism to resist restriction by human APOBEC3G. Curr. Biol. 18, 819-824. doi: 10.1016/j.cub.2008.04.073

Harris, R. S., Bishop, K. N., Sheehy, A. M., Craig, H. M., Petersen-Mahrt, S. K., Watt, I. N., et al. (2003). DNA deamination mediates innate immunity to retroviral infection. Cell 113, 803-809. doi: 10.1016/S0092-8674(03)00423-9

Harris, R. S., Petersen-Mahrt, S. K., and Neuberger, M. S. (2002). RNA editing enzyme APOBEC1 and some of its homologs can act as DNA mutators. Mol. Cell 10, 1247-1253. doi: 10.1016/S1097-2765(02)00742-6

Hasham, M. G., Donghia, N. M., Coffey, E., Maynard, J., Snow, K. J., Ames, J., et al. (2010). Widespread genomic breaks generated by activation-induced cytidine deaminase are prevented by homologous recombination. Nat. Immunol. 11, 820826. doi: 10.1038/ni.1909

Henriet, S., Mercenne, G., Bernacchi, S., Paillart, J. C., and Marquet, R. (2009). Tumultuous relationship between the human immunodeficiency virus type 1 viral infectivity factor (Vif) and the human APOBEC-3G and APOBEC-3F restriction factors. Microbiol. Mol. Biol. Rev. 73, 211-232. doi: 10.1128/MMBR.00040-08

Henry, M., Terzian, C., Peeters, M., Wain-Hobson, S., and Vartanian, J. P. (2012). Evolution of the primate APOBEC3A cytidine deaminase gene and identification of related coding regions. PLoS ONE 7:e30036. doi: 10.1371/journal.pone. 0030036

Ho, Y. C., Shan, L., Hosmane, N. N., Wang, J., Laskey, S. B., Rosenbloom, D. I., et al. (2013). Replication-competent noninduced proviruses in the latent reservoir increase barrier to HIV-1 cure. Cell 155, 540-551. doi: 10.1016/j.cell.2013. 09.020

Hultquist, J. F., Lengyel, J. A., Refsland, E. W., Larue, R. S., Lackey, L., Brown, W. L., et al. (2011). Human and rhesus APOBEC3D, APOBEC3F, APOBEC3G, and APOBEC3H demonstrate a conserved capacity to restrict Vif-deficient HIV-1. J. Virol. 85, 11220-11234. doi: 10.1128/JVI.05238-11

Iio, K., Nagasawa, Y., Iwatani, H., Yamamoto, R., Horii, A., Okuzaki, D., et al. (2010). Microarray analysis of tonsils in immunoglobulin A nephropathy patients. Biochem. Biophys. Res. Commun. 393, 565-570. doi: 10.1016/j.bbrc.2010.01.120

Ikeda, T., Ohsugi, T., Kimura, T., Matsushita, S., Maeda, Y., Harada, S., et al. (2008). The antiretroviral potency of APOBEC1 deaminase from small animal species. Nucleic Acids Res. 36, 6859-6871. doi: 10.1093/nar/gkn802

Imahashi, M., Izumi, T., Watanabe, D., Imamura, J., Matsuoka, K., Ode, H., et al. (2014). Lack of association between intact/deletion polymorphisms of the APOBEC3B gene and HIV-1 risk. PLoS ONE 9:e92861. doi: 10.1371/journal.pone.0092861

Imai, K., Slupphaug, G., Lee, W. I., Revy, P., Nonoyama, S., Catalan, N., et al. (2003). Human uracil-DNA glycosylase deficiency associated with profoundly impaired immunoglobulin class-switch recombination. Nat. Immunol. 4, 1023-1028. doi: $10.1038 /$ ni974 
Iwasaki, A., and Pillai, P. S. (2014). Innate immunity to influenza virus infection. Nat. Rev. Immunol. 14, 315-328. doi: 10.1038/nri3665

Jarmuz, A., Chester, A., Bayliss, J., Gisbourne, J., Dunham, I., Scott, J., et al. (2002). An anthropoid-specific locus of orphan C to U RNA-editing enzymes on chromosome 22. Genomics 79, 285-296. doi: 10.1006/geno.2002.6718

Jin, X., Brooks, A., Chen, H., Bennett, R., Reichman, R., and Smith, H. (2005). APOBEC3G/CEM15 (hA3G) mRNA levels associate inversely with human immunodeficiency virus viremia. J. Virol. 79, 11513-11516. doi 10.1128/JVI.79.17.11513-11516.2005

Kieffer, T. L., Kwon, P., Nettles, R. E., Han, Y., Ray, S. C., and Siliciano, R. F. (2005) $\mathrm{G}->\mathrm{A}$ hypermutation in protease and reverse transcriptase regions of human immunodeficiency virus type 1 residing in resting CD4+ T cells in vivo. J. Virol. 79, 1975-1980. doi: 10.1128/JVI.79.3.1975-1980.2005

Kim, E. Y., Bhattacharya, T., Kunstman, K., Swantek, P., Koning, F. A., Malim, M. H., et al. (2010). Human APOBEC3G-mediated editing can promote HIV-1 sequence diversification and accelerate adaptation to selective pressure. J. Virol. 84, 10402-10405. doi: 10.1128/JVI.01223-10

Knoepfel, S. A., Salisch, N. C., Huelsmann, P. M., Rauch, P., Walter, H., and Metzner, K. J. (2008). Comparison of G-to-A mutation frequencies induced by APOBEC3 proteins in $\mathrm{H} 9$ cells and peripheral blood mononuclear cells in the context of impaired processivities of drug-resistant human immunodeficiency virus type 1 reverse transcriptase variants. J. Virol. 82, 6536-6545. doi: 10.1128/JVI 00554-08

Kohli, R. M., Maul, R. W., Guminski, A. F., Mcclure, R. L., Gajula, K. S., Saribasak, H., et al. (2010). Local sequence targeting in the AID/APOBEC family differentially impacts retroviral restriction and antibody diversification. J. Biol. Chem. 285, 40956-40964. doi: 10.1074/jbc.M110.177402

Koning, F. A., Newman, E. N., Kim, E. Y., Kunstman, K. J., Wolinsky, S. M., and Malim, M. H. (2009). Defining APOBEC3 expression patterns in human tissues and hematopoietic cell subsets. J. Virol. 83, 9474-9485. doi: 10.1128/JVI.01089-09

Kourteva, Y., De Pasquale, M., Allos, T., Mcmunn, C., and D’aquila, R. T. (2012). APOBEC3G expression and hypermutation are inversely associated with human immunodeficiency virus type 1 (HIV-1) burden in vivo. Virology 430, 1-9. doi: 10.1016/j.virol.2012.03.018

Land, A. M., Ball, T. B., Luo, M., Pilon, R., Sandstrom, P., Embree, J. E., et al. (2008). Human immunodeficiency virus (HIV) type 1 proviral hypermutation correlates with CD4 count in HIV-infected women from Kenya. J. Virol. 82, 8172-8182. doi: 10.1128/JVI.01115-08

LaRue, R. S., Jonsson, S. R., Silverstein, K. A., Lajoie, M., Bertrand, D., El-Mabrouk N., et al. (2008). The artiodactyl APOBEC3 innate immune repertoire shows evidence for a multi-functional domain organization that existed in the ancestor of placental mammals. BMC Mol. Biol. 9:104. doi: 10.1186/1471-2199-9-104

Lau, P. P., Xiong, W. J., Zhu, H. J., Chen, S. H., and Chan, L. (1991). Apolipoprotein B mRNA editing is an intranuclear event that occurs posttranscriptionally coincident with splicing and polyadenylation. J. Biol. Chem. 266, 20550-20554.

Lecossier, D., Bouchonnet, F., Clavel, F., and Hance, A. J. (2003). Hypermutation of HIV-1 DNA in the absence of the Vif protein. Science 300:1112. doi: $10.1126 /$ science. 1083338

Liang, G., Kitamura, K., Wang, Z., Liu, G., Chowdhury, S., Fu, W., et al. (2013). RNA editing of hepatitis B virus transcripts by activation-induced cytidine deaminase. Proc. Natl. Acad. Sci. U.S.A. 110, 2246-2251. doi: 10.1073/pnas.1221921110

Liao, W., Hong, S. H., Chan, B. H., Rudolph, F. B., Clark, S. C., and Chan, L. (1999). APOBEC-2, a cardiac- and skeletal muscle-specific member of the cytidine deaminase supergene family. Biochem. Biophys. Res. Commun. 260, 398-404. doi: 10.1006/bbrc.1999.0925

Luo, K., Wang, T., Liu, B., Tian, C., Xiao, Z., Kappes, J., et al. (2007). Cytidine deaminases APOBEC3G and APOBEC3F interact with human immunodeficiency virus type 1 integrase and inhibit proviral DNA formation. J. Virol. 81, 7238-7248. doi: 10.1128/JVI.02584-06

Machida, K., Cheng, K. T., Pavio, N., Sung, V. M., and Lai, M. M. (2005). Hepatitis C virus E2-CD81 interaction induces hypermutation of the immunoglobulin gene in B cells. J. Virol. 79, 8079-8089. doi: 10.1128/JVI.79.13.8079-8089.2005

Machida, K., Cheng, K. T., Sung, V. M., Shimodaira, S., Lindsay, K. L., Levine, A. M., et al. (2004). Hepatitis C virus induces a mutator phenotype: enhanced mutations of immunoglobulin and protooncogenes. Proc. Natl. Acad. Sci. U.S.A. 101, 4262-4267. doi: 10.1073/pnas.0303971101

Mahieux, R., Suspene, R., Delebecque, F., Henry, M., Schwartz, O., Wain-Hobson, S., et al. (2005). Extensive editing of a small fraction of human T-cell leukemia virus type 1 genomes by four APOBEC3 cytidine deaminases. J. Gen. Virol. 86, 2489-2494. doi: 10.1099/vir.0.80973-0

Malim, M. H. (2009). APOBEC proteins and intrinsic resistance to HIV-1 infection. Philos. Trans. R. Soc. Lond. B Biol. Sci. 364, 675-687. doi: 10.1098/rstb.2008.0185 Mangeat, B., Turelli, P., Caron, G., Friedli, M., Perrin, L., and Trono, D. (2003). Broad antiretroviral defence by human APOBEC3G through lethal editing of nascent reverse transcripts. Nature 424, 99-103. doi: 10.1038/nature01709

Mariani, R., Chen, D., Schrofelbauer, B., Navarro, F., Konig, R., Bollman, B., et al. (2003). Species-specific exclusion of APOBEC3G from HIV-1 virions by Vif. Cell 114, 21-31. doi: 10.1016/S0092-8674(03)00515-4

Matsumoto, T., Marusawa, H., Endo, Y., Ueda, Y., Matsumoto, Y., and Chiba, T. (2006). Expression of APOBEC2 is transcriptionally regulated by NF-kappaB in human hepatocytes. FEBS Lett. 580, 731-735. doi: 10.1016/j.febslet.2005. 12.081

Mbisa, J. L., Barr, R., Thomas, J. A., Vandegraaff, N., Dorweiler, I. J., Svarovskaia, E. S., et al. (2007). Human immunodeficiency virus type 1 cDNAs produced in the presence of APOBEC3G exhibit defects in plus-strand DNA transfer and integration. J. Virol. 81, 7099-7110. doi: 10.1128/JVI.00272-07

Mikl, M. C., Watt, I. N., Lu, M., Reik, W., Davies, S. L., Neuberger, M. S., et al. (2005). Mice deficient in APOBEC2 and APOBEC3. Mol. Cell. Biol. 25, 7270-7277. doi: 10.1128/MCB.25.16.7270-7277.2005

Miyagi, E., Opi, S., Takeuchi, H., Khan, M., Goila-Gaur, R., Kao, S., et al. (2007). Enzymatically active APOBEC3G is required for efficient inhibition of human immunodeficiency virus type 1. J. Virol. 81, 13346-13353. doi: 10.1128/JVI.01361-07

Monajemi, M., Woodworth, C. F., Zipperlen, K., Gallant, M., Grant, M. D., and Larijani, M. (2014). Positioning of APOBEC3G/F mutational hotspots in the human immunodeficiency virus genome favors reduced recognition by CD8+ $\mathrm{T}$ Cells. PLoS ONE 9:e93428. doi: 10.1371/journal.pone.0093428

Morgan, H. D., Dean, W., Coker, H. A., Reik, W., and Petersen-Mahrt, S. K. (2004). Activation-induced cytidine deaminase deaminates 5-methylcytosine in DNA and is expressed in pluripotent tissues: implications for epigenetic reprogramming. J. Biol. Chem. 279, 52353-52360. doi: 10.1074/jbc.M407695200

Mous, K., Jennes, W., Camara, M., Seydi, M., Daneau, G., Mboup, S., et al. (2012). Expression analysis of LEDGF/p75, APOBEC3G, TRIM5alpha, and tetherin in a Senegalese cohort of HIV-1-exposed seronegative individuals. PLoS ONE 7:e33934. doi: 10.1371/journal.pone.0033934

Mulder, L. C., Harari, A., and Simon, V. (2008). Cytidine deamination induced HIV-1 drug resistance. Proc. Natl. Acad. Sci. U.S.A. 105, 5501-5506. doi: 10.1073/pnas.0710190105

Muramatsu, M., Kinoshita, K., Fagarasan, S., Yamada, S., Shinkai, Y., and Honjo, T. (2000). Class switch recombination and hypermutation require activationinduced cytidine deaminase (AID), a potential RNA editing enzyme. Cell 102, 553-563. doi: 10.1016/S0092-8674(00)00078-7

Muramatsu, M., Sankaranand, V. S., Anant, S., Sugai, M., Kinoshita, K., Davidson, N. O., et al. (1999). Specific expression of activation-induced cytidine deaminase (AID), a novel member of the RNA-editing deaminase family in germinal center B cells. J. Biol. Chem. 274, 18470-18476. doi: 10.1074/jbc.274.26.18470

Mussil, B., Suspene, R., Aynaud, M. M., Gauvrit, A., Vartanian, J. P., and WainHobson, S. (2013). Human APOBEC3A isoforms translocate to the nucleus and induce DNA double strand breaks leading to cell stress and death. PLoS ONE 8:e73641. doi: 10.1371/journal.pone.0073641

Navaratnam, N., Morrison, J. R., Bhattacharya, S., Patel, D., Funahashi, T., Giannoni, F., et al. (1993). The p27 catalytic subunit of the apolipoprotein B mRNA editing enzyme is a cytidine deaminase. J. Biol. Chem. 268, 20709-20712.

Newman, E. N., Holmes, R. K., Craig, H. M., Klein, K. C., Lingappa, J. R., Malim, M. H., et al. (2005). Antiviral function of APOBEC3G can be dissociated from cytidine deaminase activity. Curr. Biol. 15, 166-170. doi: 10.1016/j.cub.2004.12.068

Norman, J. M., Mashiba, M., Mcnamara, L. A., Onafuwa-Nuga, A., Chiari-Fort, E., Shen, W., et al. (2011). The antiviral factor APOBEC3G enhances the recognition of HIV-infected primary T cells by natural killer cells. Nat. Immunol. 12, 975-983. doi: 10.1038/ni.2087

Okazaki, I. M., Hiai, H., Kakazu, N., Yamada, S., Muramatsu, M., Kinoshita, K., et al. (2003). Constitutive expression of AID leads to tumorigenesis. J. Exp. Med. 197, 1173-1181. doi: 10.1084/jem.20030275

Okazaki, I. M., Kotani, A., and Honjo, T. (2007). Role of AID in tumorigenesis. Adv. Immunol. 94, 245-273. doi: 10.1016/S0065-2776(06)94008-5 
Ooms, M., Brayton, B., Letko, M., Maio, S. M., Pilcher, C. D., Hecht, F. M., et al. (2013). HIV-1 Vif adaptation to human APOBEC3H haplotypes. Cell Host Microbe 14, 411-421. doi: 10.1016/j.chom.2013.09.006

Pace, C., Keller, J., Nolan, D., James, I., Gaudieri, S., Moore, C., et al. (2006). Population level analysis of human immunodeficiency virus type 1 hypermutation and its relationship with APOBEC3G and vif genetic variation. J. Virol. 80, 9259-9269. doi: 10.1128/JVI.00888-06

Peng, G., Greenwell-Wild, T., Nares, S., Jin, W., Lei, K. J., Rangel, Z. G., et al. (2007). Myeloid differentiation and susceptibility to HIV-1 are linked to APOBEC3 expression. Blood 110, 393-400. doi: 10.1182/blood-2006-10-051763

Pennings, J. L., Van Dartel, D. A., Pronk, T. E., Hendriksen, P. J., and Piersma, A. H. (2010). Identification by gene coregulation mapping of novel genes involved in embryonic stem cell differentiation. Stem Cells Dev. 20, 115-126. doi: $10.1089 /$ scd.2010.0181

Petersen-Mahrt, S. K., and Neuberger, M. S. (2003). In vitro deamination of cytosine to uracil in single-stranded DNA by apolipoprotein B editing complex catalytic subunit 1 (APOBEC1). J. Biol. Chem. 278, 19583-19586. doi: 10.1074/jbc.C300114200

Petit, V., Guetard, D., Renard, M., Keriel, A., Sitbon, M., Wain-Hobson, S. et al. (2009). Murine APOBEC1 is a powerful mutator of retroviral and cellular RNA in vitro and in vivo. J. Mol. Biol. 385, 65-78. doi: 10.1016/j.jmb.2008. 10.043

Phalora, P. K., Sherer, N. M., Wolinsky, S. M., Swanson, C. M., and Malim, M. H. (2012). HIV-1 replication and APOBEC3 antiviral activity are not regulated by $\mathrm{P}$ bodies. J. Virol. 86, 11712-11724. doi: 10.1128/JVI.00595-12

Piantadosi, A., Humes, D., Chohan, B., Mcclelland, R. S., and Overbaugh, J. (2009). Analysis of the percentage of human immunodeficiency virus type 1 sequences that are hypermutated and markers of disease progression in a longitudinal cohort, including one individual with a partially defective Vif. J. Virol. 83, 7805-7814. doi: 10.1128/JVI.00280-09

Pido-Lopez, J., Wang, Y., Seidl, T., Babaahmady, K., Vaughan, R., and Lehner, T. (2009). The effect of allogeneic in vitro stimulation and in vivo immunization on memory CD4(+) T-cell APOBEC3G expression and HIV-1 infectivity. Eur. J. Immunol. 39, 1956-1965. doi: 10.1002/eji.200939228

Pido-Lopez, J., Whittall, T., Wang, Y., Bergmeier, L. A., Babaahmady, K., Singh, M., et al. (2007). Stimulation of cell surface CCR5 and CD40 molecules by their ligands or by HSP70 up-regulates APOBEC3G expression in CD4(+) T cells and dendritic cells. J. Immunol. 178, 1671-1679. doi: 10.4049/jimmunol.178. 3.1671

Pillai, S. K., Abdel-Mohsen, M., Guatelli, J., Skasko, M., Monto, A., Fujimoto, K., et al. (2012). Role of retroviral restriction factors in the interferon-alpha-mediated suppression of HIV-1 in vivo. Proc. Natl. Acad. Sci. U.S.A. 109, 3035-3040. doi: 10.1073/pnas.1111573109

Pion, M., Granelli-Piperno, A., Mangeat, B., Stalder, R., Correa, R., Steinman, R. M., et al. (2006). APOBEC3G/3F mediates intrinsic resistance of monocytederived dendritic cells to HIV-1 infection. J. Exp. Med. 203, 2887-2893. doi 10.1084/jem.20061519

Popp, C., Dean, W., Feng, S., Cokus, S. J., Andrews, S., Pellegrini, M., et al. (2010) Genome-wide erasure of DNA methylation in mouse primordial germ cells is affected by AID deficiency. Nature 463, 1101-1105. doi: 10.1038/nature08829

Prochnow, C., Bransteitter, R., Klein, M. G., Goodman, M. F., and Chen, X. S. (2007). The APOBEC-2 crystal structure and functional implications for the deaminase AID. Nature 445, 447-451. doi: 10.1038/nature05492

Rai, K., Huggins, I. J., James, S. R., Karpf, A. R., Jones, D. A., and Cairns, B. R. (2008). DNA demethylation in zebrafish involves the coupling of a deaminase, a glycosylase, and gadd45. Cell 135, 1201-1212. doi: 10.1016/j.cell.2008.11.042

Reddy, K., Winkler, C. A., Werner, L., Mlisana, K., Abdool Karim, S. S., Ndung'u, T., et al. (2010). APOBEC3G expression is dysregulated in primary HIV-1 infection and polymorphic variants influence CD4+ T-cell counts and plasma viral load. AIDS 24, 195-204. doi: 10.1097/QAD.0b013e3283353bba

Refsland, E. W., Stenglein, M. D., Shindo, K., Albin, J. S., Brown, W. L., and Harris, R. S. (2010). Quantitative profiling of the full APOBEC3 mRNA repertoire in lymphocytes and tissues: implications for HIV-1 restriction. Nucleic Acids Res. 38, 4274-4284. doi: 10.1093/nar/gkq174

Renard, M., Henry, M., Guetard, D., Vartanian, J. P., and Wain-Hobson, S. (2010). APOBEC1 and APOBEC3 cytidine deaminases as restriction factors for hepadnaviral genomes in non-humans in vivo. J. Mol. Biol. 400, 323-334. doi: 10.1016/j.jmb.2010.05.029
Revy, P., Muto, T., Levy, Y., Geissmann, F., Plebani, A., Sanal, O., et al. (2000) Activation-induced cytidine deaminase (AID) deficiency causes the autosomal recessive form of the Hyper-IgM syndrome (HIGM2). Cell 102, 565-575. doi: 10.1016/S0092-8674(00)00079-9

Robbiani, D. F., Bothmer, A., Callen, E., Reina-San-Martin, B., Dorsett, Y., Difilippantonio, S., et al. (2008). AID is required for the chromosomal breaks in $\mathrm{c}$-myc that lead to $\mathrm{c}-\mathrm{myc} / \mathrm{IgH}$ translocations. Cell 135, 1028-1038. doi: 10.1016/j.cell.2008.09.062

Robbiani, D. F., Bunting, S., Feldhahn, N., Bothmer, A., Camps, J., Deroubaix, S., et al. (2009). AID produces DNA double-strand breaks in non-Ig genes and mature B cell lymphomas with reciprocal chromosome translocations. Mol. Cell 36, 631-641. doi: 10.1016/j.molcel.2009.11.007

Rose, K. M., Marin, M., Kozak, S. L., and Kabat, D. (2005). Regulated production and anti-HIV type 1 activities of cytidine deaminases APOBEC3B, 3F, and 3G. AIDS Res. Hum. Retroviruses 21, 611-619. doi: 10.1089/aid.2005.21.611

Rosenberg, B. R., Hamilton, C. E., Mwangi, M. M., Dewell, S., and Papavasiliou, F. N. (2011). Transcriptome-wide sequencing reveals numerous APOBEC1 mRNAediting targets in transcript 3' UTRs. Nat. Struct. Mol. Biol. 18, 230-236. doi: 10.1038/nsmb.1975

Rosenberg, B. R., and Papavasiliou, F. N. (2007). Beyond SHM and CSR: AID and related cytidine deaminases in the host response to viral infection. Adv. Immunol. 94, 215-244. doi: 10.1016/S0065-2776(06)94007-3

Sadler, H. A., Stenglein, M. D., Harris, R. S., and Mansky, L. M. (2010). APOBEC3G contributes to HIV-1 variation through sublethal mutagenesis. J. Virol. 84, 73967404. doi: 10.1128/JVI.00056-10

Santiago, M. L., Benitez, R. L., Montano, M., Hasenkrug, K. J., and Greene, W. C. (2010). Innate retroviral restriction by Apobec3 promotes antibody affinity maturation in vivo. J. Immunol. 185, 1114-1123. doi: 10.4049/jimmunol.1001143

Sarkis, P. T., Ying, S., Xu, R., and Yu, X. F. (2006). STAT1-independent cell typespecific regulation of antiviral APOBEC3G by IFN-alpha. J. Immunol. 177, 45304540. doi: 10.4049/jimmunol.177.7.4530

Sawyer, S. L., Emerman, M., and Malik, H. S. (2004). Ancient adaptive evolution of the primate antiviral DNA-editing enzyme APOBEC3G. PLoS Biol. 2:E275. doi: 10.1371/journal.pbio.0020275

Schumacher, A. J., Hache, G., Macduff, D. A., Brown, W. L., and Harris, R. S. (2008). The DNA deaminase activity of human APOBEC3G is required for Ty1, MusD, and human immunodeficiency virus type 1 restriction. J. Virol. 82, 2652-2660. doi: 10.1128/JVI.02391-07

Sheehy, A. M., Gaddis, N. C., Choi, J. D., and Malim, M. H. (2002). Isolation of a human gene that inhibits HIV-1 infection and is suppressed by the viral Vif protein. Nature 418, 646-650. doi: 10.1038/nature00939

Simm, M., Shahabuddin, M., Chao, W., Allan, J. S., and Volsky, D. J. (1995). Aberrant Gag protein composition of a human immunodeficiency virus type 1 vif mutant produced in primary lymphocytes. J. Virol. 69, 4582-4586.

Singh, K. K., Wang, Y., Gray, K. P., Farhad, M., Brummel, S., Fenton, T., et al. (2013). Genetic variants in the host restriction factor APOBEC3G are associated with HIV-1-related disease progression and central nervous system impairment in children. J. Acquir. Immune Defic. Syndr. 62, 197-203. doi: 10.1097/QAI.0b013e31827ab612

Souza, T. M., Rodrigues, D. Q., Passaes, C. P., Barreto-De-Souza, V., Aguiar, R. S., Temerozo, J. R., et al. (2011). The nerve growth factor reduces APOBEC3G synthesis and enhances HIV-1 transcription and replication in human primary macrophages. Blood 117, 2944-2952. doi: 10.1182/blood-2010-05-287193

Stenglein, M. D., Burns, M. B., Li, M., Lengyel, J., and Harris, R. S. (2010). APOBEC3 proteins mediate the clearance of foreign DNA from human cells. Nat. Struct. Mol. Biol. 17, 222-229. doi: 10.1038/nsmb.1744

Stopak, K. S., Chiu, Y. L., Kropp, J., Grant, R. M., and Greene, W. C. (2007). Distinct patterns of cytokine regulation of $\mathrm{APOBEC} 3 \mathrm{G}$ expression and activity in primary lymphocytes, macrophages, and dendritic cells. J. Biol. Chem. 282, 3539-3546. doi: 10.1074/jbc.M610138200

Sui, Y., Zhu, Q., Gagnon, S., Dzutsev, A., Terabe, M., Vaccari, M., et al. (2010) Innate and adaptive immune correlates of vaccine and adjuvant-induced control of mucosal transmission of SIV in macaques. Proc. Natl. Acad. Sci. U.S.A. 107, 9843-9848. doi: 10.1073/pnas.0911932107

Suspene, R., Aynaud, M. M., Guetard, D., Henry, M., Eckhoff, G., Marchio, A., et al. (2011a). Somatic hypermutation of human mitochondrial and nuclear DNA by APOBEC3 cytidine deaminases, a pathway for DNA catabolism. Proc. Natl. Acad. Sci. U.S.A. 108, 4858-4863. doi: 10.1073/pnas.1009687108 
Suspene, R., Aynaud, M. M., Koch, S., Pasdeloup, D., Labetoulle, M., Gaertner, B., et al. (2011b). Genetic editing of herpes simplex virus 1 and Epstein-Barr herpesvirus genomes by human APOBEC 3 cytidine deaminases in culture and in vivo. J. Virol. 85, 7594-7602. doi: 10.1128/JVI.00290-11

Suspene, R., Guetard, D., Henry, M., Sommer, P., Wain-Hobson, S., and Vartanian, J. P. (2005). Extensive editing of both hepatitis B virus DNA strands by APOBEC3 cytidine deaminases in vitro and in vivo. Proc. Natl. Acad. Sci. U.S.A. 102, 83218326. doi: 10.1073/pnas.0408223102

Tanaka, Y., Marusawa, H., Seno, H., Matsumoto, Y., Ueda, Y., Kodama, Y., et al. (2006). Anti-viral protein APOBEC3G is induced by interferon-alpha stimulation in human hepatocytes. Biochem. Biophys. Res. Commun. 341, 314-319. doi: 10.1016/j.bbrc.2005.12.192

Teng, B., Burant, C. F., and Davidson, N. O. (1993). Molecular cloning of an apolipoprotein B messenger RNA editing protein. Science 260, 1816-1819. doi: 10.1126/science.8511591

Thielen, B. K., Mcnevin, J. P., Mcelrath, M. J., Hunt, B. V., Klein, K. C., and Lingappa, J. R. (2010). Innate immune signaling induces high levels of TC-specific deaminase activity in primary monocyte-derived cells through expression of APOBEC3A isoforms. J. Biol. Chem. 285, 27753-27766. doi: 10.1074/jbc.M110.102822

Trapp, S., Derby, N. R., Singer, R., Shaw, A., Williams, V. G., Turville, S. G., et al. (2009). Double-stranded RNA analog poly(I:C) inhibits human immunodeficiency virus amplification in dendritic cells via type I interferon-mediated activation of APOBEC3G. J. Virol. 83, 884-895. doi: 10.1128/JVI.00023-08

Turelli, P., Mangeat, B., Jost, S., Vianin, S., and Trono, D. (2004). Inhibition of hepatitis B virus replication by APOBEC3G. Science 303, 1829. doi: 10.1126/science.1092066

Ulenga, N. K., Sarr, A. D., Thakore-Meloni, S., Sankale, J. L., Eisen, G., and Kanki, P. J. (2008). Relationship between human immunodeficiency type 1 infection and expression of human APOBEC3G and APOBEC3F. J. Infect. Dis. 198, 486-492. doi: $10.1086 / 590212$

Valcke, H. S., Bernard, N. F., Bruneau, J., Alary, M., Tsoukas, C. M., and Roger, M. (2006). APOBEC3G genetic variants and their association with risk of HIV infection in highly exposed Caucasians. AIDS 20, 1984-1986. doi: 10.1097/01.aids.0000247124.35129.e1

Vartanian, J. P., Guetard, D., Henry, M., and Wain-Hobson, S. (2008). Evidence for editing of human papillomavirus DNA by APOBEC3 in benign and precancerous lesions. Science 320, 230-233. doi: 10.1126/science.1153201

Vartanian, J. P., Meyerhans, A., Asjo, B., and Wain-Hobson, S. (1991). Selection, recombination, and G- - - -A hypermutation of human immunodeficiency virus type 1 genomes. J. Virol. 65, 1779-1788.

Vazquez-Perez, J. A., Ormsby, C. E., Hernandez-Juan, R., Torres, K. J., and ReyesTeran, G. (2009). APOBEC3G mRNA expression in exposed seronegative and early stage HIV infected individuals decreases with removal of exposure and with disease progression. Retrovirology 6:23. doi: 10.1186/1742-4690-6-23

Vetter, M. L., and D'Aquila, R. T. (2009). Cytoplasmic APOBEC3G restricts incoming Vif-positive human immunodeficiency virus type 1 and increases two-long terminal repeat circle formation in activated T-helper-subtype cells. J. Virol. 83, 8646-8654. doi: 10.1128/JVI.00020-09

Vonica, A., Rosa, A., Arduini, B., and Brivanlou, A. H. (2010). APOBEC2, a selective inhibitor of TGFbeta signaling, regulates left-right axis specification during early embryogenesis. Dev. Biol. 350, 13-23. doi: 10.1016/j.ydbio.2010.09.016

Wang, F. X., Huang, J., Zhang, H., Ma, X., and Zhang, H. (2008). APOBEC3G upregulation by alpha interferon restricts human immunodeficiency virus type 1 infection in human peripheral plasmacytoid dendritic cells. J. Gen. Virol. 89, 722-730. doi: 10.1099/vir.0.83530-0

Wang, X., Ao, Z., Chen, L., Kobinger, G., Peng, J., and Yao, X. (2012). The cellular antiviral protein APOBEC3G interacts with HIV-1 reverse transcriptase and inhibits its function during viral replication. J. Virol. 86, 3777-3786. doi: 10.1128/JVI.06594-11

Wang, Y., Bergmeier, L. A., Stebbings, R., Seidl, T., Whittall, T., Singh, M., et al. (2009). Mucosal immunization in macaques upregulates the innate APOBEC $3 \mathrm{G}$ anti-viral factor in $\mathrm{CD} 4(+)$ memory $\mathrm{T}$ cells. Vaccine 27, 870-881. doi: 10.1016/j.vaccine.2008.11.084
Watashi, K., Liang, G., Iwamoto, M., Marusawa, H., Uchida, N., Daito, T., et al. (2013). Interleukin-1 and tumor necrosis factor-alpha trigger restriction of hepatitis $B$ virus infection via a cytidine deaminase activation-induced cytidine deaminase (AID). J. Biol. Chem. 288, 31715-31727. doi: 10.1074/jbc.M113.501122

Wei, M., Shinkura, R., Doi, Y., Maruya, M., Fagarasan, S., and Honjo, T. (2011). Mice carrying a knock-in mutation of Aicda resulting in a defect in somatic hypermutation have impaired gut homeostasis and compromised mucosal defense. Nat. Immunol. 12, 264-270. doi: 10.1038/ni.1991

Wichroski, M. J., Robb, G. B., and Rana, T. M. (2006). Human retroviral host restriction factors APOBEC3G and APOBEC3F localize to mRNA processing bodies. PLoS Pathog. 2:e41. doi: 10.1371/journal.ppat.0020041

Wissing, S., Montano, M., Garcia-Perez, J. L., Moran, J. V., and Greene, W. C. (2011). Endogenous APOBEC3B restricts LINE-1 retrotransposition in transformed cells and human embryonic stem cells. J. Biol. Chem. 286, 36427-36437. doi: 10.1074/jbc.M111.251058

Wood, N., Bhattacharya, T., Keele, B. F., Giorgi, E., Liu, M., Gaschen, B., et al. (2009). HIV evolution in early infection: selection pressures, patterns of insertion and deletion, and the impact of APOBEC. PLoS Pathog. 5:e1000414. doi: 10.1371/journal.ppat.1000414

Woodford, N., and Ellington, M. J. (2007). The emergence of antibiotic resistance by mutation. Clin. Microbiol. Infect. 13, 5-18. doi: 10.1111/j.1469-0691.2006. 01492.x

Yamanaka, S., Balestra, M. E., Ferrell, L. D., Fan, J., Arnold, K. S., Taylor, S., et al. (1995). Apolipoprotein B mRNA-editing protein induces hepatocellular carcinoma and dysplasia in transgenic animals. Proc. Natl. Acad. Sci. U.S.A. 92, 8483-8487. doi: 10.1073/pnas.92.18.8483

Yamane, A., Resch, W., Kuo, N., Kuchen, S., Li, Z., Sun, H. W., et al. (2011). Deep-sequencing identification of the genomic targets of the cytidine deaminase AID and its cofactor RPA in B lymphocytes. Nat. Immunol. 12, 62-69. doi: 10.1038/ni.1964

Yewdell, J. W., and Nicchitta, C. V. (2006). The DRiP hypothesis decennial: support, controversy, refinement and extension. Trends Immunol. 27, 368-373. doi: 10.1016/j.it.2006.06.008

Ying, S., Zhang, X., Sarkis, P. T., Xu, R., and Yu, X. (2007). Cell-specific regulation of APOBEC3F by interferons. Acta Biochim. Biophys. Sin. (Shanghai) 39, 297-304. doi: 10.1111/j.1745-7270.2007.00275.x

Yu, Q., Konig, R., Pillai, S., Chiles, K., Kearney, M., Palmer, S., et al. (2004). Singlestrand specificity of APOBEC3G accounts for minus-strand deamination of the HIV genome. Nat. Struct. Mol. Biol. 11, 435-442. doi: 10.1038/nsmb758

Zhang, H., Yang, B., Pomerantz, R. J., Zhang, C., Arunachalam, S. C., and Gao, L. (2003). The cytidine deaminase CEM15 induces hypermutation in newly synthesized HIV-1 DNA. Nature 424, 94-98. doi: 10.1038/nature01707

Zhao, M., Geng, W., Jiang, Y., Han, X., Cui, H., Dai, D., et al. (2010). The associations of hA3G and hA3B mRNA levels with HIV disease progression among HIVinfected individuals of China. J. Acquir. Immune Defic. Syndr. 53 (Suppl. 1), S4-S9. doi: 10.1097/QAI.0b013e3181c7d349

Conflict of Interest Statement: The authors declare that the research was conducted in the absence of any commercial or financial relationships that could be construed as a potential conflict of interest.

Received: 27 June 2014; accepted: 24 September 2014; published online: 13 October 2014.

Citation: Moris A, Murray S and Cardinaud S (2014) AID and APOBECs span the gap between innate and adaptive immunity. Front. Microbiol. 5:534. doi: 10.3389/fmicb.2014.00534

This article was submitted to Virology, a section of the journal Frontiers in Microbiology.

Copyright (C) 2014 Moris, Murray and Cardinaud. This is an open-access article distributed under the terms of the Creative Commons Attribution License (CC BY). The use, distribution or reproduction in other forums is permitted, provided the original author(s) or licensor are credited and that the original publication in this journal is cited, in accordance with accepted academic practice. No use, distribution or reproduction is permitted which does not comply with these terms. 